\title{
Enseñanzas climáticas en la obra de $\mathrm{Kant}^{1}$
}

\author{
Jorge OlCINA CANTOS \\ Departamento de Análisis Geográfico Regional y Geografía Física \\ Universidad de Alicante \\ jorge.olcina@ua.es
}

Recibido: 30 de abril del 2014

Enviado a evaluar: 8 de mayo del 2014

Aceptado: 17 de julio del 2014

\section{RESUMEN}

Kant ha pasado a la historia del pensamiento universal como el gran filósofo de la razón, del idealismo transcendental, pero como docente universitario impartió enseñanzas de geografía durante cuarenta años. El estudio y comprensión del "espacio" constituye uno de los ejes de la filosofía kantiana, porque el filósofo de Köningsberg considera al espacio como uno de los ejes básicos del conocimiento humano, de ahí que no resulte extraño comprender el interés de Kant por la geografía. Sus lecciones de Geografía Física son un compendio de los conocimiento geográfico en época ilustrada y en sus páginas hay varios apartados dedicados al entendimiento de los fenómenos atmosféricos, que resultan realmente innovadores para la ciencia climática. La explicación de los vientos alisios, de los monzones, del fenómeno de brisas y, en general, del movimiento del viento suponen un avance en la evolución de la climatología.

Palabras clave: Espacio, geografía, ilustración, atmósfera, viento, enseñanzas climáticas

\section{Climatic lessons in Kant's work}

\begin{abstract}
Kant has happened to history of the universal thought as the great philosopher of reason and transcendental idealism, but as a university lecturer he taught geography lessons during forty years. The study and understanding of "space" is one of the axes of the Kantian philosophy, because the philosopher of Königsberg considers space as one of the basic areas of human knowledge, hence it is not strange to understand Kant's interest in geography. His lessons of Physical Geography are a compendium of geographical knowledge in enlightened age. In this work are several sections dedicated to the understanding of atmospheric phenomena, that are truly innovative for climate science. The explanation of the trade winds, the monsoons, the phenomenon of breezes and, generally, about wind movement repreent an advande in the evolution of climatology.
\end{abstract}

Key words: Space, geography, enlightened epoch, atmosphere, wind, climate lessons

${ }^{1}$ Este artículo forma parte de las investigaciones llevadas a cabo en el seno del grupo de investigación en "Historia y Clima" de la Universidad de Alicante, bajo dirección del prof. Armando Alberola Romá, desarrollados en el marco del proyecto I+D (HAR2013-44972-P). 


\section{Leçons climatiques dans les ceuvres de Kant}

\section{RÉSUMÉ}

Kant s'est passé à l'histoire de la pensée universelle comme le grand philosophe de la raison et de l'idéalisme transcendantal, mais comme une université leçons professeur de géographie, j'ai enseigné pendant quarante ans. L'étude et la compréhension de «l'espace» est l'un des axes de la philosophie kantienne, le philosophe de Königsberg Parce considère l'espace comme l'un des domaines fondamentaux de la connaissance humaine, il n'est pas étonnant donc pour comprendre l'intérêt de Kant en géographie. Ses leçons de géographie physique sont un recueil de connaissances géographiques en âge éclairé. Dans ce travail plusieurs sections sont dédiées à la compréhension des phénomènes atmosphériques, qui sont vraiment innovante pour la science du climat. L'explication des alizés, les moussons, le phénomène des brises et, règle générale, sur une advande mouvement repreent du vent dans l'évolution de la climatologie.

Mots clés: L'espace, la géographie, epoch éclairé, l'atmosphère, le vent, les leçons de climat

\section{INTRODUCCIÓN}

El siglo XVIII conoce importantes avances en las disciplinas atmosféricas. Climatología y meteorología experimentan un impulso decisivo que permitirá su consolidación como ciencias algunas décadas después. La explicación, bajo los principios de la nueva física newtoniana, relativos a la circulación de vientos y otros fenómenos atmosféricos, la propia mejora en los aparatos de medición de variables meteorológicas, la validación de las condiciones climáticas de diferentes zonas climáticas del mundo en relación con las noticias y anotaciones de los viajes de exploradores y navegantes, sitúa a la meteorología y la climatología en el universo de las disciplinas que se verán beneficiadas por el ambiente de renovación de las ciencias que impulsará la Ilustración en la Europa del s.XVIII y que contará con figuras señaladas del campo de la física, la astronomía y la matemática, (Hadley, Reamur, Celsius, Pascal, Franklin y los españoles Ulloa y Jorge Juan). Estos autores nos han dejado, en sus escritos, una amplia relación de nuevas aportaciones a las disciplinas atmosféricas. Menos conocidas son las propuestas que llevan a cabo algunos filósofos ilustrados al avance de las ciencias meteorológica y climática, pero que son realmente relevantes, bien por los intentos de interpretación de fenómenos atmosféricos y de hechos climáticos o bien porque contribuyen a difundir y asentar conocimientos generados por la ciencia ilustrada. Todo ello permitirá configurar un corpus teórico básico para la consolidación de la meteorología y la climatología como disciplinas científicas, en el marco del positivismo decimonónico y en igualdad de condiciones con otras ciencias físicas y naturales. Es el caso de los trabajos sobre ciencias naturales de pensadores como Hume, Leibniz, Voltaire, Rousseau, Montesquieu, Kant o Herder. En todos ellos, empero, y a pesar del ambiente de pensamiento ilustrado y racional en que desarrollan sus reflexiones, es cierto que se manifiesta la influencia del ambientalismo a la hora de explicar la distribución del ser 
humano en la superficie terrestre y la influencia del clima en dicho reparto (Urteaga, 1993).

En la historia del pensamiento geográfico, Kant apenas merece mención en la evolución de la disciplina que tiene lugar entre Varenio y los alemanes Humboldt y Ritter. Y su aportación se resume en pocas líneas, señalando que impartió unas lecciones de geografía en la Universidad de Koningsberg durante varios años, que reuniría en un tratado de "Geografía Física". Es una visión parcial de la aportación del filósofo alemán al pensamiento geográfico; entre otros aspectos, porque ese tratado fue el resultado de la recopilación de apuntes de clase tomados por alguno de sus discípulos y compilados -en dos manuscritos diferentes (vid. infra)-, al final de la trayectoria académica del filósofo alemán. De manera que no es una obra concebida $a b$ initio como un manual académico al uso. Por otra parte, el mismo título de la obra geográfica de Kant -"Geografía Física"- nada tiene que ver con la conceptualización posterior de la rama física de la geografía, tal y como se entiende en la actualidad ${ }^{2}$.

Kant tuvo el mérito de reunir en sus escritos sobre "ciencia natural" conocimientos geográficos de la época y de apuntar explicación de hechos y fenómenos naturales en el marco del racionalismo ilustrado en el que se desarrollará la obra del filósofo de Konigsberg. Geografía física es, para Kant, geografía en sentido global: la explicación de la Tierra como morada del ser humano y de las formas diversas que presenta esta relación dinámica entre medio y hombre. La Geografía física es, para Kant, la descripción física del medio donde el ser humano lleva a cabo sus actividades. Como señala Ortega (2000, p. 111) para Kant la geografía física es el fundamento del conocimiento del mundo; y el mundo es el escenario en el que se desarrolla el juego de las habilidades del ser humano. Y ello porque como indica el filósofo prusiano en su obra "Idea de una Historia Universal en sentido cosmopolita" (1784) "la naturaleza ha querido que el hombre logre completamente de sí mismo todo aquello que sobrepasa el ordenamiento mecánico de su existencia animal y que no participe de ninguna otra felicidad o perfección que la que él mismo, libre de instinto, se procure por la propia razón", de manera que el paso inicial para la obtención del progreso, entendido como desarrollo de todas las diposiciones del ser humano, es el conocimiento del medio natural en el que éste se desenvuelve.

Este es el interés de Kant por la geografía y el legado geográfico que nos ha dejado el filósofo prusiano es digno de reconocimiento, no sólo por las descripciones de lugares, ni por la incorporación de un método novedoso en el análisis geográfico, sino por las interpretaciones de hechos y fenómenos geográficos bajo la lógica de la razón y esto será especialmente notable en los escritos que dedicará a la explicación de aspectos atmosféricos y climáticos.

\footnotetext{
${ }^{2}$ Vid. Kant, I. Physical Geography [Rink's edition, 1802]. Vol. I, Introduction. §1, 2, 3, 4, y 5. (In. Watkins, E. (edit.) (2012) Natural Science. The Cambridge edition of the Works of Immanuel Kant in translation. San Diego, University of California, 818 p.
} 


\section{UN DESTACADO INTERÉS POR LA DISCIPLINA GEOGRÁFICA}

Kant ha pasado a la historia del pensamiento humano como uno de sus filósofos más importantes, creador del llamado "idealismo transcendental" basado en la crítica y en los postulados ilustrados defensores de la razón como eje de pensamiento. Menos conocida es su faceta como profesor de geografía, a pesar de que esta tarea ocupó gran parte de su labor como profesor en la Universidad de Koningsberg.

La relación de Kant con la geografía se desarrolla durante cuarenta años a lo largo de la prolongada vida del filósofo alemán; desde el anuncio del primer curso de Geografía Física que tiene lugar en el verano de 1756 en la Universidad de Koningsberg, hasta la última lección sobre esta materia que impartiría en 1796. Abarca, por tanto, toda su vida de pensamiento más fértil.

Es frecuente encontrar en los estudios sobre la obra filosófica de Kant una división "temática" establecida a partir de la edición de sus obras filosóficas consideradas más importantes (las "Críticas"). De este modo, se distingue entre una etapa "pre-crítica" (1755-1781) y una posterior "crítica" (1781-1790). En este contexto, la obra geográfica de Kant discurre en los dos períodos y recogerá, por tanto, influencias de ambos, especialmente de la etapa "pre-crítica" en la que Kant reflexiona sobre las cuestiones del espacio y del tiempo, así como de diversos aspectos de la Naturaleza.

El interés de Kant por los temas de la Naturaleza llevará al filósofo a elaborar una serie de escritos, de gran interés en el contexto de evolución epistemológica de las ciencias naturales. Estos escritos que dedica el filósofo a la reflexión sobre cuestiones de la Naturaleza comprenden quince manuscritos sobre temas diversos ${ }^{4}$ : mecánica y sus efectos sobre la Naturaleza; rotación terrestre y alteración entre el día y la noche; evolución histórica de la Tierra; causas y efectos de los terremotos, a raíz del ocurrido el 1 de noviembre de 1755 en Lisboa; teoría del Cielo, meditaciones sobre el fuego; teoría de los vientos; reflexiones sobre el carácter húmedo de los vientos del oeste que circulan sobre el Atlántico; teoría sobre las bolas de fuego; reflexiones sobre los volcanes en la Luna y sobre la influencia de la Luna en el tiempo atmosférico. Y a ellos se unirá los denominados "apuntes" de Geografía Física que en realidad son textos recogidos por discípulos del filósofo, puesto que Kant nunca recopiló un manuscrito que pudiere ser editado, como tal, y seguido como manual de referencia en sus cursos universitarios de geografía, como era costumbre en la universidad ilustrada.

No es extraña esta relación de Kant con la disciplina geográfica, en el contexto de la época de la Ilustración en la que el filósofo alemán desarrolla su obra, y mucho menos en el propio decurso de la reflexión kantiana, desde sus primeros momentos.

${ }^{3}$ Critica de la razón pura (1781 y 1787); Crítica de la razón práctica (1788) y Crítica del juicio (1790).

${ }^{4}$ La edición de estos trabajos de Kant sobre ciencias de la Naturaleza se puede consultar en Watkins, E. (edit.) (2012) Natural Science. The Cambridge edition of the Works of Immanuel Kant in translation. San Diego, University of California, 818 p. 
Kant siempre tuvo un interés por el desarrollo de las dos disciplinas que consideraba básicas en el universo del conocimiento del ser humano: la historia y la geografía ${ }^{5}$. Ambas suponen el estudio de dos variables fundamentales en el sistema de coordenadas de conocimiento del ser humano: el tiempo y el espacio. Se trata de conceptos esenciales para la comprensión científica de las cosas, según Kant. Desde el nivel más bajo de conocimiento, que implica advertir las representaciones producidas por la acción de las cosas en nuestros sentidos, es necesario contar con un sistema de relaciones en el espacio y en el tiempo para poder tener sensaciones de las mismas. El espacio y el tiempo permiten la diversificación y la unificación de la materia indeterminada de la apariencia. Ambas variables son condiciones necesarias "a priori" de la experiencia sensible y ello permite ordenar la intuición empírica. Como señala Russell (2010), los hechos de la geografía y de la historia son para Kant proposiciones empíricas, es decir, no es posible conocerlos salvo con ayuda de la percepción sensitiva, bien propia o bien de alguien cuyo testimonio se acepta.

Pero Kant va más allá y otorga "condición" al tiempo y el espacio en la distinción entre los sentidos externos o percepción de los objetos que están fuera del ser humano y el sentido interno por medio del cual percibimos estados internos sobre esos objetos. En este sentido, el espacio es la forma de todas las apariencias externas: todos los objetos externos al ser humano tienen que ser representados como existentes en el espacio; el tiempo, por su parte, es la forma propia del sentido interno, de la intuición de nosotros mismos y de nuestro estado interno. Es esta segunda condición, -el tiempo como condición formal de toda aparicicia-, la que prima en el sistema del conocimiento humano de las cosas. Espacio y tiempo son, para Kant, intuiciones "a priori" para el conocimiento de las cosas, no son resultado de la experiencia. Este aspecto aparta al filósofo alemán de la concepción de Hume sobre el aprendizaje. Kant distingue entre apariencia y realidad a la hora de conocer un objeto, un hecho, puesto que puede haber realidadesque no afectan a los sentidos, que no pertenecen a la realidad empírica y, en ese caso, "no pueden ser" en el espacio y en el tiempo. La apariencia de las cosas, para Kant, no es que "parezcan" estar en el espacio, es que "son" en el espacio y en el tiempo. Si no, no son realidades empíricas. No hay equívocos en cuanto al mundo sensible: el espacio y el tiempo son las formas y las condiciones de la experiencia externa e interna, es decir, del mundo exterior e interior (Belaval, 1982). Para el filósofo alemán, el mundo exterior sólo produce la materia de la sensación, pero nuestro aparato mental ordena esta materia en espacio y tiempo y proporciona los conceptos por medio de los cuales entendemos la experiencia

\footnotetext{
${ }^{5}$ A estas dos disciplinas, básicas para la formación del ser humano en opinión del filósofo alemán, unirá Kant también la antropología; no en vano esta última disciplina ocupará un buen número de lecciones impartidas a lo largo de su carrera académica en la Universidad de Konigsberg.
} 
(Russell, 2010). Espacio y tiempo son para Kant, subjetivos; son parte de nuestro aparato de percepción; no son conceptos, son formas de intuición, son formas a priori ${ }^{6}$.

El espacio, para Kant, cumple cuatro condiciones: 1) no es un concepto empírico abstraído de experiencias externas; se presupone al referir las sensaciones a algo externo. 2) es una representación necesaria a priori, que está por debajo de todas las percepciones externas, puesto que no podemos imaginar que no haya espacio. 3) solamente hay un espacio; si hablamos de "espacios" nos referimos, realmente, a partes de un sólo espacio. 4) es una magnitud infinita dada y, por ello, es una intuición ${ }^{7}$. Estas cuatro condiciones son esenciales dentro del sistema de conocimiento del ser humano.

Esto enlaza con la concepción kantiana del conocimiento humano que para el filósofo de Koninsgberg nace de dos fuentes principales: la facultad de recibir impresiones de los objetos y la facultad de pensar los objetos por medio de conceptos. Ambas facultades de complementan para el conocimiento de las cosas. Como indica el propio Kant "los pensamientos sin contenido son vacíos; las intuiciones sin conceptos son ciegas". En palabras de Ortega, el filósofo alemán, "ve el mundo no directamente, sino reflejado en su yo, convertido en hecho de conciencia, en imagen o idea". (Ortega, 1983)

$\mathrm{Y}$ en este sentido, Kant afirmará que es posible una ciencia pura de la naturaleza; esto es, aquel conocimiento de los objetos que hay en ella que son a la vez resultado de la experiencia y, al mismo tiempo, responden a unas condiciones "a priori", a unas leyes universales de la naturaleza cognoscibles "a priori". Estas leyes son impuestas por el ser humano, pero al mismo tiempo objetivas porque son válidas para todo el ámbito de la experiencia, o sea, para la naturaleza en cuanto medio de los objetos posibles de la experiencia. Y ello es así porque el entendimiento es capaz de conocer por sus conceptos y juicios cosas que no son dadas en la experiencia y de conocerlas en su categoría de "en sí" y no como fenómenos dados en el espaco y en el tiempo. El entendimiento adquiere, pues, una completa autonomía frente a la intuición (Belaval, 1982). Y así se adquiere un conocimiento perfecto de las cosas (vid. Figura 1).

\footnotetext{
${ }^{6}$ A la explicación del espacio y tiempo y sus formas de conocimiento dedicaría Kant gran parte de una de sus obras principales de pensamiento, la Crítica de la razón pura (1781 y 1787) y, asimismo, de los Prolegómenos (1783).

Para Russell (2010) este último criterio ("el espacio es imaginado como una magnitud infinita dada") es propio de una persona como Kant que vivía en una región llana, como Koeningsberg, en la desembocadora del río Pregel, pero es dificil imaginar como podría imaginarla un habitante de un valle alpino. (Russell, 2010, p. 396-397).
} 
Figura 1. La geografía en el sistema de conocimiento humano, según Kant.

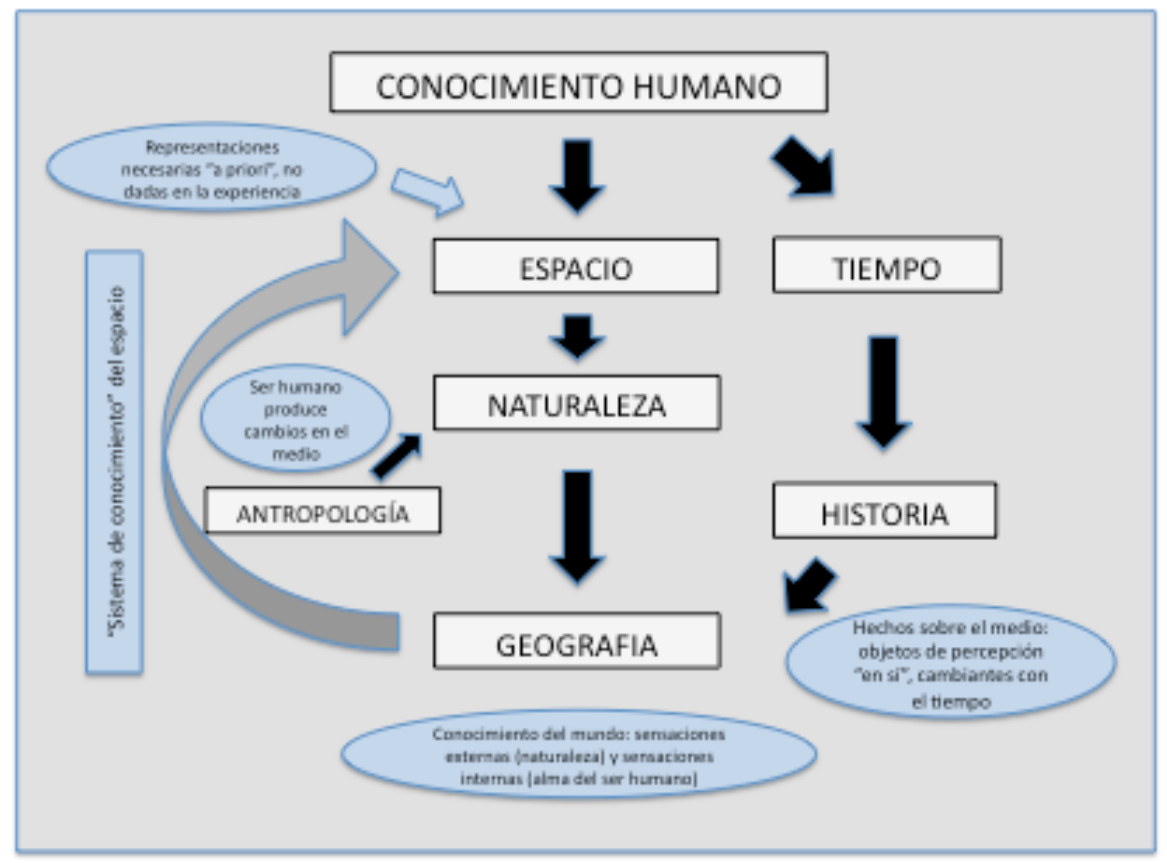

Fuente: Elaboración propia

Para Kant la naturaleza es un estado primitivo a superar por el ser humano o la humanidad. En su concepción teleológica de la naturaleza Kant nos habla de las tres funciones que ésta cumple: el designio de realizarse a plenitud, la valoración ética que sobre ella debe tener el ser humano y que le debe impedir ir contra sus designios y, por último, la garantía de progreso humano y de obtención la paz perpetua. No obstante el ser humano, mediante el empleo de la razón, del pensamiento liberador que persigue la Ilustración, puede ayudar a convivir con esta concepción finalista de la Naturaleza. Y este proceso discurre a lo largo de la Historia, que es, en definitiva, una realización paulatina de los fines ideales que prescribe la razón práctica; es el espacio del desarrollo de las potencialidades humanas y de la unificación de las acciones conducidas hacia el fin de la razón impuesto en la naturaleza y corresponde a la razón práctica elucidar y enunciar ese fin.

En este contexto hay que entender el interés de Kant por la geografía. El ser humano debe conocer los hechos que están -y son- en el espacio; y esos hechos, a menudo complejos, deben organizarse, jerarquizarse para poderlos entender. Los objetos de percepción son causados, para Kant, por "cosas -en-sí", esto es, por sucesos del mundo físico (Russell, 2010). Y, además estos sucesos no son inmutables, son cambiantes en el tiempo, y en ese cambio, propio de la evolución de los fenómenos de la Naturaleza, ha podido jugar un papel destacado el ser humano, de 
ahi la necesidad de su estudio dentro de la disciplina geográfica. Lo objetivo, los hechos, en la filosofía kantiana, sólo tienen sentido si hay alguien que los busca, si hay alguien que va hacia ellos. Y este alguien es la vida humana como razón vital. Para Kant, "la vida del hombre es en su raíz ocuparse de las cosas del mundo, no consigo mismo." (Ortega y Gasset, 1983)

En efecto, Kant cree necesario que en el estudio de la Geografía física se incluya al hombre como uno de los fenómenos que produce cambios en el medio (Glacken, 1996). De manera que el concepto de Geografía física de Kant es, en suma, el concepto de geografía como estudio del medio físico y la acción del hombre sobre aquel, que quedaría plenamente asentado en la disciplina geográfica a partir de la obra de Humboldt.

Para Kant enseñar geografía significa enseñar a conocer "el gran laboratorio de la naturaleza, sus instrumentos, sus tentativas" (Fatone, 2003). Sin conocimientos geográficos, el ser humano queda limitado; con ellos descubre que más allá de todas las diferencias es "hijo de la Naturaleza". Nada cultivará y formará mejor el buen sentido del ser humano que los conocimientos geográficos según el filósofo alemán.

Y ello desde la premisa básica del carácter dinámico de la Tierra y de superación de la idea de designio extendida en el pensamiento occidental desde época griega, lo que llevará a Kant a afirmar que "la historia de la Tierra resulta de acontecimientos históricos, no de causas finales" o, más allá, "la historia del hombre se desarrolla sobre un planeta que tiene su propia historia" y a subrayar que la superficie terrestre no está hecha como fin para el hombre, no es el resultado de un designio, es un producto de la historia geológica (Glaken, 1996, 494-5). Este último aspecto llevará al filósofo a incorporar algunos epígrafes en su Geografía Física, dedicados a explicar la evolución de la Tierra y de sus condiciones ambientales.

Con estas ideas sobre el espacio y el papel de la geografía para Kant debe interpretarse el propio contenido y la importancia de las lecciones de "Geografía Física" que nos dejó el filósofo alemán en la evolución posterior de las disciplinas científicas vinculadas con el análisis y descripción de los hechos que se dan en la Naturaleza.

Un profesor universitario que imparte clases de geografía durante cuarenta años de su vida académica, que recopila los conocimientos existentes de esta disciplina en unos apuntes manuscritos -aunque nunca los editaría personalmente como tratado- y que en esos apuntes incluye aportaciones novedosas para la explicación de hechos y fenómenos de la Naturaleza puede ser considerado, con todo merecimiento, un geógrafo; uno de los autores básicos en la consolidación de la geografía como ciencia. Como indica Ortega (2000), el rastro de Kant forma parte del proceso de fundación de la geografía moderna, como disciplina puramente descriptiva y como disciplina del escenario terrestre. Kant marca el transito necesario entre la representación del mundo cosmográfica y cartográfica de Varenio y los ensayos de Humboldt que darán integridad científica a la disciplina geográfica. 


\section{LA GEOGRAFÍA FÍSICA DE KANT: MANUSCRITOS QUE SE COMPLEMENTAN}

A la hora de valorar las enseñanzas y aportaciones de Kant en el campo de la meteorología y climatología es preciso conocer el contexto en el que se produce la recopilación de materiales que culminaría en la edición de la "Geografía Física" y que no estuvo exenta de vicisitudes. En efecto, en 1801, dos discípulos de Kant, Johann Jakob Wilhelm y Giottgried Vollmer publicaron, sin el permiso del filósofo, un primer volumen de una obra bajo el título de "Geografía Física". La edición completa de esta obra, en cuatro volúmenes, se llevaría a cabo entre 1801 y 1805. Ediciones posteriores, revisadas, de estos textos se editarían bajo la etiqueta "Joh.Jak.WilhVollmer's Physical Geografphy based on Kantian ideas" hasta 1817. El propio título de estas ediciones manifiesta su carácter de libro no autorizado por el propio filósofo. Este hecho movió a Kant, en sus últimos años de vida, a permitir la edición de sus apuntes sobre Geografía Física. Dada la delicada salud del fílósofo, ya septuagenario en el tránsito del siglo, confió la labor de recopilación a su amigo y profesor de Teología en la misma Universidad de Koningsberg, Friedrich Theoder Rink.

En la labor de compilación del manuscrito, Rink tuvo como documento base unos apuntes $\operatorname{propios}^{8}$ del filósofo que éste le cedió para llevar a cabo este empeño; pero además pudo consultar varias transcripciones de apuntes tomados por estudiantes durante los años de impartición de sus lecciones de geografía ${ }^{9}$. En 1802, Rink editó, en Koningsberg, las lecciones de geografía de Kant bajo el título "Immanuel Kants Physische Geographie". La publicación de este volumen no deja de sorprender a algún estudioso ${ }^{10}$ de la obra de Kant, al considerar que Kant nunca dictaba apuntes, de forma literal, en sus clases que si resultaban atractivas y pudieron mantenerse como curso ofertado durante cuarenta años era, precisamente, por el carácter ameno, repleto de ejemplos y anécdotas, que el filósofo alemán imprimía a los temas tratados. Del manuscrito editado por Rink se critica también que los apuntes de los alumnos consultados, junto al propio manuscrito que le cedió Kant, correspondían a una época muy temprana de impartición de las lecciones del filósofo; amén de otros debates existentes sobre los problemas de la traducción al inglés del propio texto en alemán de Rink. Entre 1911 y 1913, Enrich Adickes llevaría a cabo una nueva edición del

\footnotetext{
${ }^{8}$ Un documento esencial para la configuración del manuscrito de la Geografía Física es el denominado "manuscrito de Holstein-Beck", perteneciente a un disciplinado alumno del filósofo que recogió los apuntes elaborados por el propio Kant, entre 1757 y 1759, para sus clases de Geografía (los denominados Diktattext manuscript) y a los que Kant añadió, de propia mano y años después, correcciones y añadidos. Holstein-Beck reunió los materiales de su manuscrito, con las anotaciones añadidas de Kant durante invierno de 1772/73.

${ }^{9}$ Vid.University of Manchester. Kant in the classroom. Materials to aid the study of Kant's lectures. (disponible en: http://www.manchester.edu/kant/notes/notesGeography.htm\#family). ${ }^{10}$ Vid. Stark, W. (2001) Immanuel Kants physische Geographie - eine Her-ausforderung?, 4th May 2001. Disponible en http://www.staff.uni-marburg.de/wstark/ws_lese4.htm.
} 
texto de Rink, tras un proceso de depuración de las fuentes manejadas originalmente por aquél ${ }^{11}$.

En el presente trabajo se han manejado las dos versiones señaladas de la Geografía Física de Kant: la de Wilhelm-Vollmer ${ }^{12}$ y la de Rink. No son manuscritos exactamente iguales y en el primero se incluyen apartados que complementan al segundo. Como se indicará más adelante, el contenido de las enseñanzas climáticas de Kant solo puede entenderse en su totalidad si se analizan los dos textos. Y, en general, esto es aplicable al resto de contenidos de la Geografía Física, puesto que el manuscrito de Wilhelm-Vollmer contiene aspectos relativos a concepto y método de trabajo de la geografía que no se contienen, o al menos no de forma tan detallada, en la versión de Rink.

La Geografía Física de Kant se organiza en dos volúmenes y tres partes principales. En el primer volumen se incluye, tras una introducción y un apartado de conceptos matemáticos preliminares, la Parte Primera de forma integra. En ella se abordan los tres elementos principales de la Naturaleza (agua, tierra y aire) y se incluye un interesante apartado, al final, sobre la historia de "los grandes cambios que ha experimentado y sigue experimentando la Tierra". A esta Parte Primera la denominará Kant, "Parte General", frente a las restantes dos partes de su obra (Partes Segunda y Tercera) que recibirán la denominación de "Parte Particular", donde se contiene la explicación de "los productos y criaturas de la Tierra". Las reflexiones y teorías explicativas sobre los fenómenos de la Naturaleza que se incluyen en la Parte Primera ("parte general") de la Geografía Física forma, tal vez, el contenido más innovador de la obra de Kant, donde hay aportación propia en la explicación de los hechos que se dan sobre la superficie terrestre.

El segundo volumen de la Geografía Física, el más extenso, está destinado, por tanto, a la descripción de "lo que se encuentra sobre la Tierra" (Partes Segunda y Tercera). Para ello, Kant sigue una línea expositiva, propia del racionalismo ilustrado, y organiza la presentación de los hechos que hay sobre la superficie terrestre en relación con los grandes reinos de la Naturaleza, esto es, seres humanos, reino animal, reino vegetal y reino mineral (Parte Segunda). Por último, en la Parte Tercera de la Geografía Física, Kant realiza un ejercicio de geografía descriptiva de los cuatro continentes reconocidos en su época (Asia, África, Europa y América), con explicación y comentarios de los países más representativos o de los que se tenían

\footnotetext{
${ }^{11}$ En 1924-25, Adickes recopilaría en un volumen los escritos sobre la Naturaleza del filósofo alemán (vid. Erich Adickes, Kant als Naturforscher, 2 vols., Berlin: de Gruyter, 1924-25). Este trabajo ha merecido una reciente edición a cargo de Eric Watkins, comentada y enriquecida con estudios temáticos, por parte de la Universidad de Cambridge (Vid. Watkins, E. (ed.) Natural Science. The Cambridge Edition of the Works of Immanuel Kant, Cambridge University Press, 818 p.). Este trabajo ha sido la base de consulta manejada, de modo principal, para la elaboración del presente estudio.

${ }^{12}$ Para la lectura de este manuscrito se ha consultado la edición italiana, llevada a cabo por Augusto Eckerlin en varios volúmenes (Geografia Fisica di Emanuele Kant, tradotta dal tedesco. 6 vols. Milano, 1807-11. Dalla tipografia di Giovanni Silvestri.)
} 
más noticias. Es de señalar que las tierras de lo que conocemos como Oceanía, se reducen al comentario, en unas breves líneas, de Nueva Holanda (Australia) dentro del capítulo dedicado a Asia.

En este segundo volumen se muestra, como señala Ortega (2000), la endeblez de las descripciones de Kant, la ausencia de una concepción o esquema básico, la mezcla de datos sobre población con informaciones pintorescas de rango etnográfico muy elemental que, frente a lo señalado para el primer volumen ("parte general". vid supra) no permite caracterizar al filósofo alemán como un geógrafo moderno. De manera que, la descripción que acompaña las Partes Segunda y Tercera de la Geografía Física, nos habla de un Kant que "no inicia la moderna geografía sino que culmina la vieja representación del mundo medieval" donde persiste el género de transmisión escrita de maravillas, portentos y cosas notables. Debe recordarse que Kant muy rara vez salía de su ciudad natal y las referencias a hechos de los reinos de la naturaleza o de los continentes y países que se describen, son un ejercicio de sistematización de las múltiples lecturas y noticias recopiladas por el filósofo a lo largo de los años de explicación de su Geografía Física en la Universidad de Koninsberg, pero no de un conocimiento de primera mano.

De manera que, en síntesis, se puede hablar de innovación, en la Parte Primera de la Geografía Física, y de tradición, en las otras dos partes a la hora de valorar la aportación a la disciplina geográfica que se contiene en la obra geográfica editada de Kant. Es innovador en la explicación de procesos de la Naturaleza, pero tradicional en la descripción de los hechos que se dan sobre la superficie terrestre. Eso, si, no se puede negar un exhaustivo trabajo de documentación a la hora de preparar los materiales que son la base de las lecciones de geografía que impartió y que iba actualizando, con anotaciones propias al margen, conforme actualizaba sus lecturas.

En efecto, la Geografía Física de Kant bebe de fuentes diversas a la hora de configurar las diferentes partes de su manuscrito. Es fundamental la influencia de Varenio y de su compendio de Geografía General en la obra del filósofo alemán. En realidad, la propia estructura de la Geografía Física de Kant sigue una distribución temática similar a la Geografía de Varenio (vid. tabla adjunta) y puede llegar a parecer una síntesis de la magna obra de Varenio en las cuestiones de geografía general. Además, la división en 3 partes en que se organiza la Geografía Física de Kant corresponde a la división de la disciplina geográfica establecida por Varenio en su Geographía Generalis (cap. I), esto es:

-Geografía General, con exposición de la forma, figura, tamaño y divisiones de la Tierra, que vendría a ser una geografía geométrica al modo establecido desde época griega (Parte Primera de la Geografía Física de Kant)

-Geografía Respectiva, con explicación de los accidentes y observaciones de lo que contiene la Tierra a modo de "geografía física o naturalista" propiamente dicha. (Parte Segunda de la Geografía Física de Kant)

-Geografía Comparativa, que correspondería con lo que sería una geografía regional (Parte Tercera de la Geografía Física de Kant). 
Como sabemos Varenio desarrolló la parte general en su obra geográfica, pero no las otras dos y es en aquélla donde se encuentran paralelismos en la distribución temática de los contenidos tratados por Kant, que vienen a ser, en muchos casos, una síntesis de los apartados sobre estas cuestiones generales de la Geografía, incluidos en la Geographía Generalis de Varenio. Hay, sin embargo, un extenso apartado sobre "geografía matemática", donde Varenio aborda la descripción detallada de los conceptos de latitud, longitud, zonas y klimatas, así como la representación cartográfica de la superficie terrestre, que Kant no trata en su Geografía Física (vid. Tabla 1).

Tabla 1. Estructura de los grandes temas tratados por Varenio y Kant en sus obras sobre geografía.

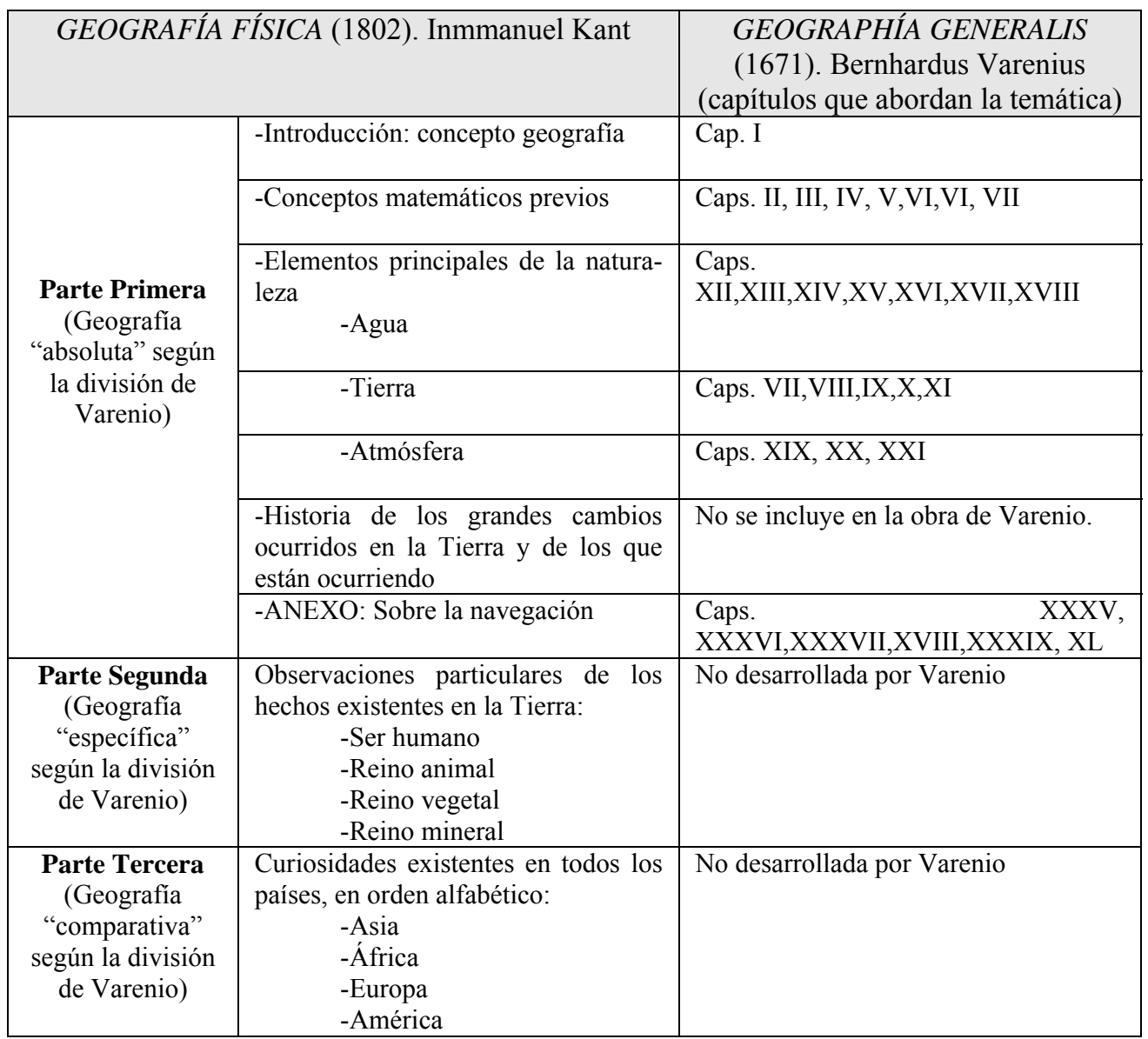

Fuente: Elaboración propia. 
Tabla 2. Principales referencias bibliográficas consultadas por Kant en su Geografía Física.

\begin{tabular}{|c|c|c|}
\hline \multicolumn{2}{|c|}{$\begin{array}{l}\text { Autores más destacados consultados por Kant en } \\
\text { su Geografía Física }\end{array}$} & $\begin{array}{l}\text { Autores más destacados } \\
\text { consultados por Kant } \\
\text { para la elaboración de } \\
\text { sus escritos sobre } \\
\text { cuestiones atmosféricas }\end{array}$ \\
\hline $\begin{array}{l}\text {-Aristóteles } \\
\text {-Herodoto } \\
\text {-Plinio el Viejo } \\
\text {-Leo Africanus } \\
\text {-Edrisi } \\
\text {-Bernhandus Varenius } \\
\text {-Isaac Newton Won Wolff } \\
\text {-Christian von Wolm } \\
\text {-Gottfried Aed John } \\
\text { Leibniz } \\
\text {-Antonio Lazaro Moro } \\
\text {-François Marie Arouet, } \\
\text { Voltaire } \\
\text {-Carl Linné y Johann } \\
\text { Joachim Lange } \\
\text {-Charles Louis de Se- } \\
\text { condat, Barón de Mon- } \\
\text { tesquieu } \\
\text {-John Woodward } \\
\text {-Philippe Bauche } \\
\text {-Horace Bénédict de } \\
\text { Saussure } \\
\text {-Johann Baptist Homann } \\
\text {-Thomas Salmon } \\
\text {-Gerhard Friedrich Müller }\end{array}$ & $\begin{array}{l}\text {-Peter Colbe } \\
\text {-Johann Lulofs } \\
\text {-Johann Georg Gmelin } \\
\text {-Johann Heinrich Gottlob von } \\
\text { Justi } \\
\text {-Erik Pontoppidan } \\
\text { - Hiob Ludolf } \\
\text {-Johann Georg Keyßler } \\
\text { - Anton Friedrich Büsching } \\
\text {-Henry Ellis } \\
\text {-Johann Jacob Scheuchzer } \\
\text {-Georg Wolfgang Krafft } \\
\text {-Jean-Baptiste Labat } \\
\text {-Wouter Schouten } \\
\text {-Jean de Thevenot } \\
\text {-Johann Jacob Schatz y } \\
\text { Johann Hübner } \\
\text {-Joseph Pitton de Tournefort } \\
\text {-Ferdinan Magellan } \\
\text {-Georg Wilhelm Steller } \\
\text {-Vitus Jonassen Bering } \\
\text {-Johann Reinhol Forster } \\
\text {-John Ray }\end{array}$ & $\begin{array}{l}\text {-Isaac Newton } \\
\text {-Antonio de Ulloa } \\
\text {-Pierre Bouguer } \\
\text {-Charles Marie de La Condo- } \\
\text { mine } \\
\text {-Benjamin Franklin } \\
\text {-Antoine Reaumur } \\
\text {-Edmund Halley } \\
\text {-Ander Celsius } \\
\text {-Daniel Fahrenheit } \\
\text {-Giovani Battista Venturi } \\
\text {-Blaise Pascal } \\
\text {-Gabriel-Philippe de la Hire } \\
\text {-Jean André de Luc } \\
\text {-Johann Heinrich Lambert } \\
\text {-Leonhard Euler } \\
\text {-Daniel Bernouilli } \\
\text {-Antoine-Laurent Lavoisier } \\
\text {-William Dampier } \\
\text {-Robert Boyle } \\
\text {-Pieter van Musschenbroek } \\
\text {-Charles François de Cister- } \\
\text { nay du Fay }\end{array}$ \\
\hline
\end{tabular}

Fuente: Elaboración propia.

Y, junto a la referencia esencial de Varenio en su obra, Kant conoce también los trabajos de científicos, pensadores, historiadores y geógrafos destacados de su época. Entre ellos, los del naturalista, matemático y erudito francés, Georges Louis Leclerc, conde de Buffon, las disertaciones del filósofo Montesquieu, los del matemático y filósofo Leibniz, los apuntes del filósofo Christian Wolff, que ejerció una gran influencia en Kant y los de los físicos y naturalistas Carl Linné, René Antoine Reaumur o Edmund Halley de gran ayuda para la preparación de sus anotaciones sobre cuestiones atmosféricas en la Geografía Física. Y, junto a ellos, Kant también se refiere en su obra geográfica a los trabajos del matemático, astrónomo y físico Johann Lulofs, profesor en la Universidad de Leiden; del ornitólogo danés Erik Pontoppidan; del minerólogo Johann Heinrich Gottlob von Justi; del geógrafo e 
historiador Thomas Salmon; del naturalista y geógrafo Johann Georg Gmelin, profesor de la Universidad de Tübingen, especialista en Asia; del buen conocedor de la realidad etíope Hiob Ludolf; del historiador Peter Colbe; del pensador Johann Georg Keyßler, especialista en geografía de Europa; del teólogo, educador y geógrafo alemán en la Universidad de Halle-Wittenberg, Anton Friedrich Büsching; del geógrafo Johann Bernhard Müller, experto en territorios polares. Todos estos autores son citados por Kant en los diversos apartados de su texto. Asimismo, Kant consulta la Enciclopedia (1751-1772) de Diderot, d'Alambert y Le Rond.

La tabla adjunta (vid. Tabla 2) reúne los autores que fueron referencia para Kant, con especial detalle de aquellos que elaboraron obras sobre geografía general o geografía descriptiva y que resultaron básicos para la confección de los apuntes de Geografía Física de Kant.

El gran mérito de la Geografía Física deKant fue el de ser, para su ápoca, la obra de sístesis editada, más exhaustiva y actualizada, sobre conocimientos de geografía existentes en la segunda mitad del siglo XVIII, y de incorporar ideas propias en la explicación de hechos del medio físico que eran novedosas en aquel momento y suponen, pues, un avance notable en el proceso de consolidación como ciencia de la disciplina geográfica y, en especial de sus ramas de análisis del medio físico, muy particularmente de la climatología.

\section{AVANCES EN METEOROLOGÍA Y CLIMATOLOGÍA DURANTE EL SIGLO XVIII}

El siglo XVIII trae una serie de avances de gran importancia para las ciencias atmosféricas, que resultarán fundamentales para consolidación de la meteorología y climatología como disciplinas científicas. Estos avances se refieren a la mejora en el instrumental y sistema de medidas de elementos climáticos, al establecimiento de las primeras redes de observación, a la explicación de fenómenos atmosféricos y mecanismos de circulación general y, por último, a la interpretación del reparto de climas en la superficie terrestre y a la influencia de éstos en los seres humanos. Kant será consciente de esos avances, como manifiestan los autores citados y y las obras de consulta que el filósofo cita en el apartado dedicado a la "Atmósfera" de su Geografía Física.

En efecto, desde mediados del siglo XVII y en las primeras décadas del XVIII una serie de investigadores contribuirán al perfeccionamiento y sistematización del instrumental y unidades de medida meteorológicas. Así, por ejemplo, antes de que concluya el siglo XVIII se dispone de las cuatro escalas termométricas más difundidas, esto es, las de Fahrenheit (1724), con importante perduración aún en el ámbito anglosajón, Reamur (1730), Celsius y la escala centígrada, estas dos últimas tenidas erróneamente por equivalentes. Hay que recordar que Anders Celsius propuso en 1742 el uso de una escala donde se atribuía el valor $100^{\circ}$ al punto de fusión del hielo y $0^{\circ}$ al de ebullición del agua, es por tanto inversa a la denominada "centígrada". Esta última sería difundida en Suecia tres años después por Linneo, aunque ya había sido manejada en esta posición por Jean-Pierre Christi en Francia en 1743, en su 
famoso "termómetro de Lyon" donde asignó el valor $0^{\circ}$ al punto de fusión del hielo y $100^{\circ}$ al de ebullición del agua.

El resultado de la puesta a punto del instrumental meteorológico favorecerá el desarrollo de observaciones atmosféricas sistemáticas durante la segunda mitad del siglo XVIII y, sobre todo, en el último cuarto de esa centuria, cuando se proponen los primeros embriones de redes o servicios meteorológicos de escala europea, como la organizada por la Sociedad Meteorológica del Palatinado (1780). En la creación y consolidación de estas redes de observación meteorológica jugarán un papel destacado las Sociedades de Medicina, debido a la relación entre el desarrollo de enfermedades y las condiciones atmosféricas de un territorio. Esta relación encontrará argumento filosófico dentro del ambientalismo que cultivarán algunos ilustrados de la época (vid. infra).

En esta centuria se formulan una serie de leyes y principios físicos que resultarán de suma importancia para la consolidación de la ciencia meteorológica. Es el caso de los hallazgos de Dalton sobre mezcla gaseosa y de Gay-Lussac (1802) acerca de la dilatación de los gases. Parecida importancia tienen en lo que respecta al viento los estudios de Hooke y Halley, y los de Castelli sobre las precipitaciones.

En relación con esta serie de avances se encuentran los intentos de explicación de la circulación atmosférica general. La formulación de modelos de circulación atmosférica general se debe, principalmente, a los ingleses y, en particular, a Edmund Halley y George Hadley. El primero había propuesto, en 1688, un primer mapa de vientos a escala planetaria y en sus estudios centra la atención en una serie de aspectos esenciales, tales como el grado de incidencia de la rotación terrestre en la circulación atmosférica, y plantea como incógnita la existencia de las calmas ecuatoriales. Llama la atención asimismo sobre el carácter estacional de los monzones y esboza una hipótesis errónea sobre circulación de vientos planetarios, pero llamada a tener una extraordinaria vigencia por su carácter didáctico, denominada "chimenea ecuatorial".

Unos años antes, en 1684, el Dr. Martin Lister había publicado en la revista Philosophical Transations un artículo dando una explicación curiosa sobre el origen de los vientos alisios. Según su teoría los "trade-winds" estaban causados por el "constante aliento de las algas" ("sargessa", lenticula marina) en el oceano" y su dirección estaba originada por el movimiento general del mar en la zona tropical. En esos años, el Dr. Gordon ofrecería otra hipótesis sobre el origen de los trade-wind. Según este médico inglés los alisios se forman en la zona ecuatoral debido a la menor gravedad del aire alli existente que hace que no siga el normal movimiento de rotación de la Tierra (de Oeste a Este) como ocurre en latitudes medias sino que se desplace en sentido contrario y genere una brisa continua de este a oeste entre los trópicos.

En 1735 Hadley propondrá un modelo de circulación atmosférica general, cuya conclusión básica es que en el hemisferio norte el flujo de vientos es norte-sur y a la inversa sucede en el hemisferio austral. Particular interés muestra Hadley en justificar el rumbo de los alisios; considera que la incurvación hacia el oeste de los alisios 
resulta de la incidencia de la rotación terrestre y del incremento de velocidad lineal a medida que se pierde latitud.

Figura 2. Representación del área afectada por los vientos alisios ("Trade-winds") y los monzones en la superficie terrestre.

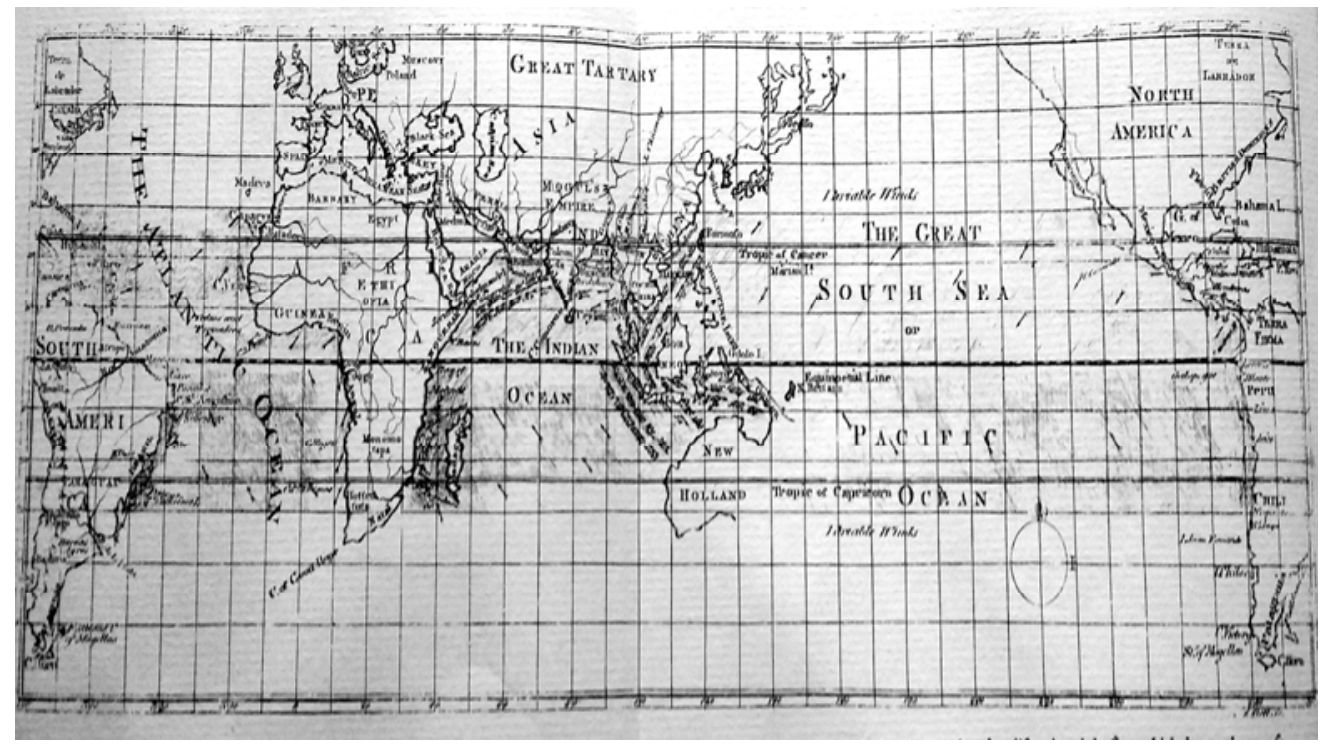

Fuente: Encyclopaedia Britannica (1 $1^{\mathrm{a}}$ edición), 1771.

En 1771, la primera edición de la Enciclopedia Británica incluiría, dentro de la voz "pneumatics" (neumática, estudio del aire), una explicación del movimiento de los vientos regulares que soplan en el ámbito intertropical, los denominados "tradewinds". En dicho texto se indica, recogiendo plenamente las ideas de Hadley, que los vientos alisios están originados por dos causas (térmica y dinámica): "One is the great heat of the equatorial region, by which alone would be produced a constant north or south wind. The other is the diurnal revolution of the earth, which would cause a perpetual tendency of the air in these warm regions from east to west" ${ }^{13}$. De la combinación de estas dos causas resulta la formación de los vientos alisios (tradewinds) que soplan de forma constante desde el SE o desde el NE. No obstante, para justificar la dirección que adquieren los alisios en algunas zonas costeras del planeta, donde se convierten en vientos de norte o de sur, según el hemisferio, se señala como origen el menor protagonismo que puede tener una de estas dos causas en esos

${ }^{13}$ Vid. Enciclopaedia Británnica 1771, vol.3. p. 499. 
territorios o bien la influencia ejercida por la presencia de factores locales como altos relieves (vid. Figura 2).

Se registra, asimismo, en este siglo avances en la descripción de fenómenos meteorológicos y en la descripción de la diversidad de climas terrestres. En relación con los primeros sobresale la explicación que se da a los ciclones tropicales por parte de Varenio, en su Geografía general, y, con posterioridad, del corsario Dampier, quien describirá un tifón en el Mar de la China; el marino Langford describe cinco huracanes en el Caribe. Antes de finalizar el siglo XVIII, Franklin se preocupará de la misma temática y hará aportaciones básicas para el conocimiento de la electricidad atmosférica y sus manifestaciones.

El s. XVIII además viene marcado por la aparición de la teoría de los climas y el origen del ambientalismo, aspectos de amplia relevancia por el amplio número de seguidores de estas ideas, donde se conjugan los hechos climáticos y los razonamiento filosóficos sobre la distribución del ser humano en la superficie terrestre. Estas dos cuestiones encuentran su marco conceptual en las obras de Buffon y Montesquieu. La influencia del clima en la explicación de las diferencias humanas, políticas y culturales del orbe terrestre fue un asunto común entre los tratadistas europeos del s. XVIII. Tres campos centrarán lo esencial del ambientalismo o determinismo del factor climático en el s.XVIII: a) La teoría étio-patológica, que hunde sus raíces en el legado hipocrático, según la cual las condiciones meteorológicas son uno de los factores determinantes de la salud humana y las diferentes características que áquellas presentan en la superficie terrestre permite establecer categorías de salubridad de los distintos ámbitos geográficos; b) La teoría de las razas, que explica la diversidad espacial de la especie humana en función de los rasgos que presenta el clima en cada lugar. Buffon, en su Historia Natural, llega a afirmar que las razas no son una entidad esencial y definida, sino el producto superficial y mudable del clima y los modos de vida; y c) una reflexión históricopolítica, que explica la diversidad cultural de las diferentes regiones del mundo como efecto de los rasgos climáticos de cada una de ellas. En El Espiritu de las Leyes, Montesquieu afirmará que el clima gobierna temperamento y costumbres, subrayando la influencia del ambiente climático en la aparición y persistencia de formas culturales (Urteaga, 1993).

Aunque estas ideas del ambientalismo climático serían cuestionadas por diversos pensadores ilustrados es cierto que la mayoría de textos de la época dedicados a explicar la distribución del ser humano sobre la superficie terrestre manifiestan la influencia de esta manera de entender las relaciones entre el medio y el hombre, incluido el propio Kant en su Geografía Física. Esta forma de plantear el reparto de grupos de población en los diferentes espacios geográficos de la Tierra perdudará, como se sabe, hasta bien entrado el siglo XX, derivando hacia posiciones realmente extremas (p.e. Semple o Huntington). 


\section{ENSEÑANZAS Y APORTACIONES A LAS CIENCIAS ATMOSFÉRICAS EN LA OBRA DE KANT}

Como se ha señalado, el análisis de las enseñanzas y aportaciones climáticas en la Geografía Física de Kant debe manejar, para disponer de una visión completa de los conocimientos impartidos en el aula por el filósofo alemán, el contenido de los dos manuscritos editados de la obra del filósofo alemán: el de Wilhelm-Vollmer y el de Rink. Y aunque es el manuscrito de Rink el que se reconoce como más propio y fidedigno de la obra de Kant, al estar compilado a partir de un bloque de apuntes del propio filósofo alemán, el primero incluye algunos contenidos de gran interés, relativos a diferentes tipos de meteoros existentes que complementan las ideas del filósofo sobre la atmósfera, su dinámica y sus elementos, así como sus manifestaciones climáticas y la propia evolución del clima terrestre.

La tabla adjunta (vid. Tabla 3) recoge los contenidos sobre aspectos meteorológicos y climáticos que se incluyen en las dos versiones de la Geografía Física de Kant.

Tabla 3. Contenidos sobre cuestiones meteorológicas y climáticas en los manuscritos de la Geografía Física de Kant

\begin{tabular}{|l|l|}
\multicolumn{1}{|c|}{$\begin{array}{c}\text { Geografía Física } \\
\text { (manuscrito de Rink, Ed. Adickes) }\end{array}$} & \multicolumn{1}{c|}{\begin{tabular}{c}
\multicolumn{1}{c|}{ Geografía Física } \\
(manuscrito de Wilhelm-Vollmer. Ed. Eckerlin)
\end{tabular}} \\
\hline -Historia de la atmósfera & -Definición y denominación de la atmósfera \\
-Sobre los vientos en general & -Dirección del viento \\
-División de los vientos según sus propiedades, & -Causa general del viento \\
humedad, sequedad, calidez, frialdad y salubridad & -Velocidad del viento \\
-Velocidad de los viento & -Fuerza del viento \\
-Sobre los alisios & -Cualidad del viento \\
-Sobre las brisas de mar y de tierra & -División del viento \\
-Sobre los monzones o vientos periódicos & -De los vientos constantes \\
-Causa de los monzones & -De los vientos periódicos \\
-Más leyes en relación a la alternancia de los & -De los vientos irregulares \\
vientos & -Del movimiento de la atmósfera en el sonido \\
-Sobre la lluvia y otras manifestaciones atmosféri- & -Meteoros húmedos \\
cas & -Meteoros ígneos \\
-Sobre la relación del tiempo atmosférico con los & -Meteoros acústicos \\
climas y las estaciones del año. & -De la temperatura y su relación con la naturaleza \\
& y situación de los lugares \\
\hline
\end{tabular}

Fuente: Elaboración propia.

Junto a los apartados dedicados en la Geografía Física, que forman el grueso fundamental de las enseñanzas climáticas e la obra de Kant, no pueden obviarse, como se ha señalado, otros escritos sobre la temática atmosférica que se incluyen en los trabajos sobre cuestiones de la Naturaleza del filósofo. Es el caso del ensayo sobre la teoría de los vientos (1756) o el relativo a "el porqué del caracter húmedo de los vientos del oeste en nuestras regiones" (1757) que sirvió de anuncio y prólogo a la 
serie de lecciones de Geografía Física que Kant comenzaría a dar regularmente en la Universidad de Koningsberg a partir de ese año. A ellos se une, en los años finales de su trayectoria universitaria, el tratado sobre la "influencia de la Luna en el tiempo atmosférico" (1794).

De entrada hay que señalar que las enseñanzas sobre la atmósfera terrestre que se incluyen en la Geografía Física de Kant, pueden entenderse como el primer manual de meteorología y climatología moderno, con unos contenidos estructurados de forma lógica, siguiendo un sistema de organización propio del racionalismo ilustrado, y donde se persigue la explicación de fenómenos a partir de las nuevas ideas de la física de Newton. Éste es, sin duda, la mayor aportación de Kant a la enseñanza de los tiempos y climas en su época: la organización sistematizada de conocimientos reunidos en un texto único. Desde la Meteorología de Aristóteles (s. IV a.C) no se disponía de un cuerpo único editado y con notable aportación propia sobre esta temática. Es cierto que en el s. XVI se había editado aportaciones extensas con explicación de fenómenos atmosféricos y hechos climáticos en las obras de algunos cronistas de Indias: Gonzalo Fernández de Oviedo, Pedro Cieza de León y, por encima de ellos, el padre José de Acosta. La propia Geographia Generalis de Varenio incluirá, como se ha señalado, tres capítulos dedicados a la explicación de aspectos atmosféricos. En el s. XVIII aparecen escritos con contenidos climáticos, de enorme rigor, en relación con la nautica (Jorge Juan, Antonio de Ulloa) o los viajes al Nuevo Mundo (La Condomine, Bouguer), así como artículos con explicación de aspectos meteorológicos que se editarán en las revistas científicas importantes del momento (Philosophical Transactions) o en las propias "Enciclopedias" que se van editando a lo largo de dicha centuria (Cyclopaedia, 1728; L'Enciclopédie de Diderot y D'Alambert, 1751-72; Enciclopaedia Britannica, 1771).

Y junto al mismo caracter de compilación de conocimientos atmosféricos de la época, la gran aportación de Kant son los intensos de explicación propia de fenomenos atmosféricos y hechos climáticos, en particular, de los aspectos relativos al movimiento del aire.

Es posible sintetizar las principales aportaciones y enseñanzas en materia climática del filósofo alemán en los siguientes aspectos:

-Tres zonas climáticas y tres capas atmosféricas

-El viento, elemento climático más destacado

-Temperaturas

-Otros meteoros

-Evolución del clima terrestre

a) Tres zonas climáticas y tres capas atmosféricas. En las primeras páginas de la Geografía Física, Kant recoge la herencia aristotélica de división de la superficie terrestre en 3 "zonas" térmicas: a) la zona tórrida, situada entre los dos trópicos y divididas en dos por la línea ecuatorial; b) las dos zonas templadas, situadas entre la 
zona tórrida y los circulos polares, llamada así "porque es alrededor de su centro donde la mayor parte de la gente y de las especies animales pueden vivir"14, y c) las dos zonas frías entre los circulos polares y los polos.

En la breve explicación de estas zonas hay, sin embargo, dos cuestiones muy significativas que merecen destacarse. Al tratar la zona templada se indica que en los lugares de esta zona próximos a los trópicos, en ambos hemisferios, hace más calor que en el propio ecuador. Recoge Kant las aportaciones que varios cronistas de Indias y algunos viajeros señalarían desde el siglo XVI a este respecto, porque en efecto en la franja de tierras próximas a la linea tropical las temperaturas son, en su conjunto, más altas que en en las proximidades del Ecuador. Ello frente a las ideas existentes con anterioridad en las que, siguiendo el criterio de Aristóteles y de algunos pensadores griegos anteriores a él, aceptaban la inhabitabilidad de la zona tórrida porque se pensaba que era la más cálida de la Tierra (Olcina, 2014). No obstante. Ahora bien, el argumento que maneja Kant para explicar el mayor calor en las tierras próximas a los trópicos frente a las existentes en las próximidades de la línea equinoccial es, esencialmente, la altura del Sol que, según el filósofo alemán, hace que en los trópicos los días sean más largos que en el Ecuador "donde día y noche son siempre iguales" $" 15$. En su explicación no señala, en ningún caso, la causa principal de este hecho térmico que es el desarrollo de una banda nubosa termoconvectiva en las tierras próximas al Ecuador, frente al mayor número de días sin apenas nubosidad de las franjas tropicales donde reina la subsidencia subtropical. Tampoco alude Kant a la diferencia térmica entre el día y la noche en esta franja subtropical, frente a la menor oscilación diaria en las tierras próximas al Ecuador. De manera que su justificación, loable para su época, sería desmontada a lo largo del siglo XX, cuando se empezaron a conocer con detalle los rasgos de la circulación atmosférica en el ámbito intertropical.

Por otra parte, Kant realiza una integración de las zonas" y los "klimata" o franjas de división territorial establecidas en función de la duración del día en ellas, a la hora de justificar la existencia de estas tres zonas. En efecto, señala el filósofo que estas zonas están determinadas en relación con la duración del día en ellas, de manera que en la zona tórrida, como se ha señalado, el día y la noche tienen una duración similar $\mathrm{y}$, asimismo, tienen el Sol en su zenit dos veces al año. La zona templada incluye los lugares, señala Kant, "en los que incluso el día más largo no alcanza 24 horas. Los países sitúa en esta zona nunca tiene el sol en su cenit, sino durante todo el año tienen día y noche cada 24 horas" $" 16$. Por último la zona fría incluye los territorios en los que el día más largo tiene una duración de medio año y que es más largo conforme se encuentre más próximo al polo. En este ámbito geográfico el sol permanece constante en el horizonte durante medio año.

\footnotetext{
${ }^{14}$ Vid. Kant, I. Physical Geography [Rink's edition, 1802]. Vol. I, Preliminary mathematical concepts. §10. (In. Watkins, E. (edit.) (2012) op. cit. supra. Nota 2).

${ }^{15}$ Vid. op. cit. supra. Nota 14. $\$ 10.3$.

${ }^{16}$ Vid. op. cit. supra. Nota 14. $\$ 10.3$.
} 
A pesar de ser un sistema empleado en las desripciones de lugares geográficos hasta bien entrado el siglo XIX, Kant no cita los "klimata" ni en el comentario de las partes que componen la superficie terrestre, ni en la propia descripción de los lugares que realizará en el apartado final de la Geografía Física. Y ello a pesar de que debía conocer su existencia en la propia obra de Varenio que el filósofo alemán tuvo como una de sus referencias literarias para preparar sus apuntes de Geografía Física, como se ha señalado.

Asimismo, Kant, defiende la existencia de 3 capas en la atmósfera que envuelve la Tierra. Una inferior, que se extiende desde el nivel del mar hasta la altura en la que la nieve no se derrite en verano. Esta capa no es igual en todas las regiones del mundo. Kant señala que la mayor altitud de las montañas en la zona calida cerca del Ecuador, favorece que allí esta capa alcance no menos que "tres cuartos de una milla germánica $^{17}$, en las latitudes proximas a los trópicos alcanza apenas la mitad de una milla germánica: en los Alpes sólo un cuarto y casi igual que el nivel del mar en el polo"18. La segunda capa, por encima de ésta, se desarrolla "hasta donde las nubes alcanzan su mayor altitud en el cielo" ${ }^{\prime 19}$. En la definición de esta capa, Kant es bastante impreciso puesto que señala que la altitud que pueden alcanzar las nubes no se puede determinar con mucha exactitud en todos los lugares del mundo, "a veces las nubes están altas y otras bajas" ${ }^{20}$; en general, precisa el filósofo, suelen aparecer por encima de la altitud de una milla germánica. En general, este capa puede alcanzar hasta donde se desarrollan los meteoros lumínosos, por tanto, para establecer su altura, según señala Kant, se pueden necesitar muchas millas germánicas"21. La tercera capa se desarrolla desde que termina la segunda hasta los confines de la atmósfera, que están determinados por la altura del crepúsculo que se encuentra a nueve millas germánicas y media"22.

Resulta muy loable e innovador, para la época en la que se desarrolla la vida de Kant, el intento de sistematización de las capas atmosféricas y de la localización de sus límites con referencias de altitud. Recordemos que desde Aristóteles se venía defendiendo la división de la atmósfera en tres capas, con diversa calidad térmica: una cálida inferior (la más próxima al suelo), una fría superior (propia de los espacios de alta montaña) y una cálida superior, por encima de aquella, cuya característica le

\footnotetext{
${ }^{17}$ La milla germánica equivalía a 1/15 parte del grado de la línea ecuatorial, esto es, 7.420,54 metros (24.345,6 pies). Esta medida variaba según las regiones alemanas. En elnorte de Alemania y Prusia se adoptó la medida tradicional danesa $(7.532,5 \mathrm{~m}$.) Tras la introducción del sistema métrico decimal, en 1872, se dió un valor fijo e igual para todo el territorio (7.500 m.).

${ }^{18}$ Vid. op. cit. supra. Nota 14. $\$ 63$.

${ }^{19}$ Vid. op. cit. supra. Nota 14. \$63.

${ }^{20}$ Debe recordarse que la clasificación de las nubes no se producirá hasta 1802, tras el fallido intento del sistema de Lamarck, con la publicación del trabajo On the modifications of clouds de Luke Howard.

${ }^{21}$ Vid. op. cit. supra. Nota 14. $\$ 63$.

${ }^{22}$ Vid. op. cit. supra. Nota 14. $\$ 63$.
} 
viene dada por la mayor proximidad al Sol. La existencia de estas tres capas, sin intentar ninguna precisión de posición altitudinal, fue manejada por el padre Acosta en su Historia Natural y Moral de las Indias para defender la habitabilidad de la zona tórrida que todavía en su época algunos estudiosos ponían en cuestión: "Por eso los filósofos afirman que las dos regiones extremas del aire, suprema e ínfima, son más cálidas, y la media, más fría. Y eso es así verdad como realmente lo muestra la experiencia, tenemos otra ayuda muy principal para hacer templada la Tórrida, y es ser por la mayor parte tierra muy alta la de las Indias y llena de muchas cumbres de montes, que con su vecindad refrescan las comarcas do caen" 23 (vid. Olcina, 2014).

Es ahora interesante el intento de ubicación latitudinal de cada una de estas tres capas y le hecho de que el filósofo precise que la altitud de la primera de ellas, donde se produce la percepción climática por parte del ser humano "no es idéntica en todas las zonas de la Tierra, siendo más elevada en las proximidades del Ecuador y casi nula en los Polos" ${ }^{24}$. Este hecho está en relación con la mayor densidad de la atmósfera en latitudes altas, más frías, y el menor en latitudes intertropicales, más cálidas. El hecho de la mayor "altura" de la atmósfera en las latitudes tropicales había sido puesto de manifiesto, por los científicos participantes en las famosas expediciones enviadas por la Academia de Ciencias francesa al Ecuador los años 30 del siglo XVIII (La Condomine, Bouguer, Godin, Jorge Juan y Antonio de Ulloa), para el cálculo de la longitud del arco de meridiano. Para ello era necesario establecer una red de triangulación geodésica, en un medio natural que no resultó nada favorable y escoger el método de medición que resultase más fiable para el cálculo de las altitudes y que, a la postre, resultó ser el barométrico (Mas Galvañ, 2013). Jorge Juan y Antonio de Ulloa en sus Observaciones ${ }^{25}$, señalarán el hecho mencionado de la mayor altura de la atmósfera en las proximidades del Ecuador que en Europa. En efecto, citando las experiencias realizadas en la costa del sur de Francia por de la Hire en 1682, y por Cassini en 1701, y comparándolas con las observaciones efectuadas por la expedición, el marino Jorge Juan concluía que: "se puede creer, que la altura de la Atmósphera en las cercanías del Equador es mayor, que en Europa"26.

Cuando en el siglo XX se precisen definitivamente las diferentes capas atmosféricas, este aspecto quedará establecido con la matización de la altitud exacta de la troposfera en las diferentes latitudes planetarias y en relación con ello, la propia ubicación de la tropopausa, debido a factores térmicos y dinámicos.

\footnotetext{
${ }^{23}$ Historia Natural y Moral de las Indias, Libro II, cap. XII

${ }^{24}$ Vid. op. cit. supra. Nota 14. \$63.

${ }^{25}$ Vid. Juan, J. y Ulloa, A.: Observaciones, libro V. De las experiencias del barómetro simple, de las quales se deduce la ley de la dilatación del Ayre, y el método de hallar la altura de los Montes, pp. 102-131. Este libro V consta de cuatro capítulos. El primero está dedicado a los experimentos realizados durante el viaje; el segundo al análisis de la ley de dilatación del aire (o ley de Boyle-Mariotte); y el tercero y cuarto a sendos métodos de hallar las alturas mediante el barómetro.

${ }^{26}$ Ibid., p. 123.
} 
b) El viento, elemento climático más destacado: ideas de Kant sobre su movimiento.

El viento y, en general, el movimiento del aire es el elemento climático más importante para Kant a tenor de la extensión que le dedica en la Geografía Física y en los mencionados escritos sobre cuestiones de la Naturaleza. Kant se interesa por conocer los rasgos de los vientos conocidos en su época y por explicar sus causas. Y es en este último aspecto donde mejor se pueden apreciar las aportaciones del filósofo alemán a las ciencias meteorológica y climática. Es lo que algún autor ha denominado la "anemología kantiana" (Pelkowski, 2004).

No es extraño que sea el viento el elemento climático que más páginas ocupe en la sección "Atmosfera" (Tercera Sección) de la Geografía Física de Kant. Recordemos la importancia de este factor atmosférico para la navegación marítima en esa época, que había favorecido la aparición de tratados de navegación en los que la descripción de los diferentes tipos de viento y, en ocasiones, la explicación de su origen ocupaba buen número de páginas; incluso dentro de la ciencia española, como atestiguan los trabajos de los mencionados eruditos ilustrados y marinos Jorge Juan y Antonio de Ulloa (expedición a América entre 1736-39 y edición de trabajos en 1748), éste último citado expresamente por el propio Kant en su tratado. A ello se une que el estudio y medición del resto de elementos climáticos tiene aún en ciernes en el siglo XVIII, el desarrollo de aparataje y de unidades de medida que permitan un estudio más detallado de temperaturas, precipitaciones, humedad o presión atmosférica. En la Geografía Física hay comentarios y descripciones de estos elementos climáticos, pero se incluyen muy pocos datos con unidad de medida de ellos ${ }^{27}$.

El filósofo incluye un pequeño párrafo para explicar el color azul del cielo que, en su opinión, se debe al resplandor blanquecino de los vapores (humedad) "visto contra el fondo negro del espacio vacío" ${ }^{28}$. En esta explicación sigue Kant los principios de la física newtoniana para la que el color no es una propiedad inherente de los objetos, como se mantenía desde Aristóteles, sino que, por el contrario, es una ilusión derivada de la respuesta de nuestro sistema visual a las emisiones de luz. Newton, en efecto, pensaba entonces que los "vapores" de la atmósfera se condensan en pequeñas "parcelas" o gotitas del tamaño adecuado como para producir el "azul excelente" de un cielo claro (Welti, 2013).

${ }^{27}$ Esto es especialmente significativo en el manuscrito de Rink. En el de Vollmer si que se hace referencia a unidades de medida de temperatura y de precpitación.

${ }^{28}$ Vid. op. cit. supra. Nota 14. §63. 
Kant utiliza una comparación para definir el viento al señalar que el aire en movimiento es como "una corriente de agua" 29 , pero no es muy preciso al mantener esta comparación y señalar que "como el mar está limitado por la dirección de la tierra firme y las montañas" ${ }^{30}$, cuando hay muchos más factores que pueden condicionar la acción del viento. Sí que acierta, por el contrario, al indicar que el choque de dos corrientes de viento opuestas, como ocurre en el mar, "produce torbellinos" ${ }^{31}$, adelantando lo que décadas después se consolidará como los mecanismos dinámicos de inestabilidad atmosférica.

Para el filósofo alemán hay tres principios principales, de raigambre exclusivamente térmica, que explicarían el funcionamiento del viento:

-El primer principio señala que el viento se mueve siempre de sectores más fríos a zonas calentadas y la duración del soplo del mismo depende de la misma duración del calentamiento existente en ese lugar. Está adelantando Kant la explicación de las brisas de mar y de tierra, generadas por diferencias de temperatura y presión atmosférica que se fijará definitivamente como causa de las mismas, a comienzos del siglo XX, en el primer teorema de V Bjerneks. Kant, sin embargo, no otorga protagonismo a la presión atmosférica en la formación de las brisas y cede a las diferencias de temperatura entre mar y tierra en los espacios de costa el papel principal de su génesis. En efecto, para Kant este desplazamiento del aire hacia las zonas más cálidas se produce porque los sectores más calientes "ceden ante esta corriente de viento, al ser más ligera que la del aire frío"32.

-El segundo principio que explica el movimiento del aire tiene que ver con la propia densidad del mismo. Para Kant si una zona se enfría poco a poco el aire situado sobre ella se contrae y deja espacio para que sea ocupado por aire más cálido. No es un razonamiento del todo correcto, puesto que el movimiento del aire, sea frío o cálido, no depende sólo de principios térmicos, sino que la presión atmosférica juega un papel básico a la hora de explicar estos desplazamientos ${ }^{33}$.

Con estos dos principios, que Kant había expuesto ya en su "Ensayo sobre la teoría de los vientos" (1756), el filósofo justifica el mecanismo de los vientos de mar a tierra (brisa diurna) y de tierra a mar (brisa nocturna) que se dan en zonas de costa o en islas. El principio que justificaría el soplo de este circuito de viento periódico sería, para Kant, simplemente térmico (vid. Figura 3).

\footnotetext{
${ }^{29}$ Vid. op. cit. supra. Nota 14. §64.

${ }^{30}$ Vid. op. cit. supra. Nota 14. § 64 .

${ }^{31}$ Vid. op. cit. supra. Nota 14. §64.

${ }^{32}$ Vid. op. cit. supra. Nota 14. § 64 .

${ }^{33}$ Vid. op. cit. supra. Nota 14. §64.
} 
Figura 3. Explicación del mecanismo de las brisas a partir de los Principios del movimiento de los vientos" de Kant (1756)

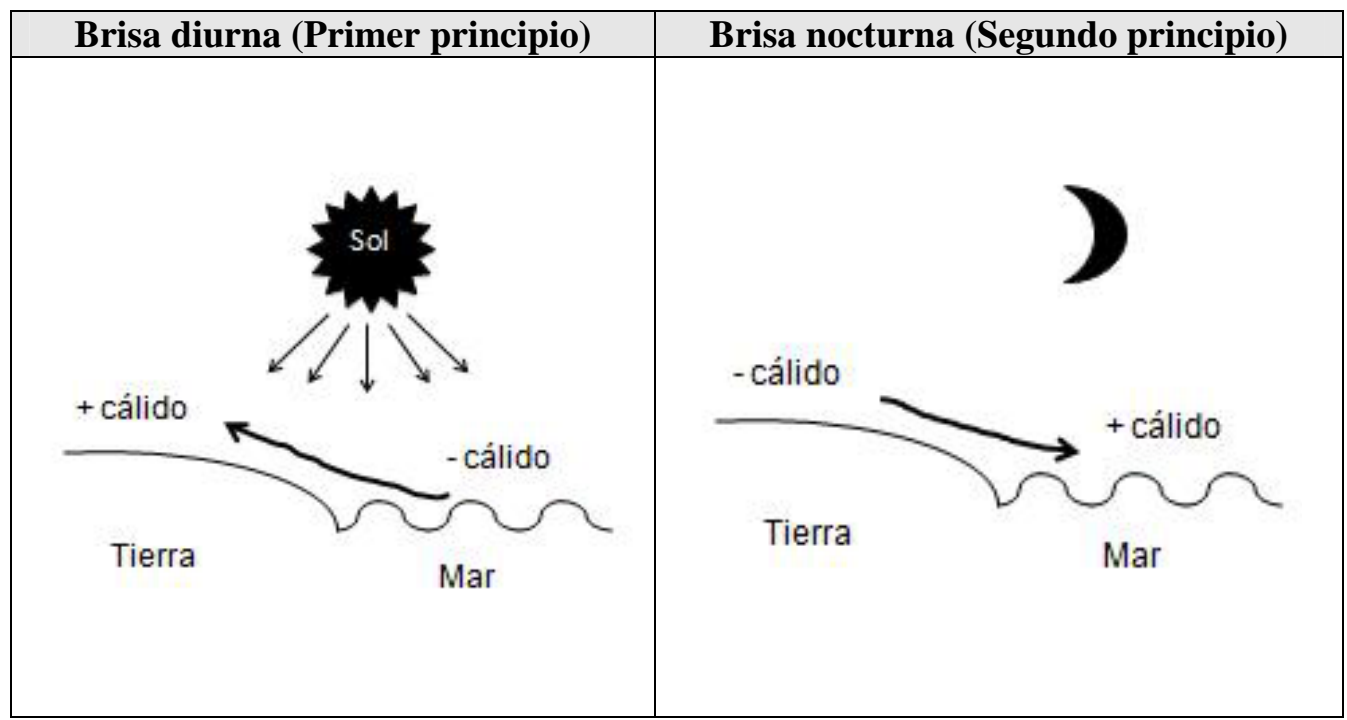

Fuente: Elaboración propia.

-Por último, como tercer principio del movimiento del viento, Kant señala que la formación de nubes de tormenta o su propio funcionamiento interno está en relación con vientos "sulfurosos y minerales que llegan a fermentar" y generan "espantosas lluvias" ${ }^{34}$; por su parte, una vez formada la tormenta, con aguaceros fuertes o granizo se originan vientos "que pueden llegar a ser muy violentos"35. La primera parte de su razonamiento se ha demostrado errónea, pero la segunda, justifica la formación de remolinos o torbellinos en una nube de desarrollo vertical.

Kant recoge en esta sección de su Geografía Física dos clasificaciones de los vientos: la primera, derivada de la rosa de los vientos utilizada por los navegantes que organiza los vientos en relación con las cuatro direcciones principales y sus fracciones entre ellas (N,S,E,W, NE, SE, SW, NW, etc.) hasta completar un total de 32 direcciones. La segunda clasificación de vientos está en relación con las propiedades físicas de éstos, es decir, su carácter húmedo o seco, frío o cálido y su condición de salubridad. El filósofo alemán hace un recorrido por los vientos regionales por él conocidos y explica sus características y los cambios que experimentan en función del recorrido que efectúen por zonas más secas o húmedas. Kant maneja, sin hacerlo explicito, el concepto de "temperatura sensible" a la hora de

\footnotetext{
${ }^{34}$ Vid. op. cit. supra. Nota 14. $\$ 64$.

${ }^{35}$ Vid. op. cit. supra. Nota 14. § 64.
} 
caracterizar la condición fría o cálida de un viento. En palabras del filósofo: "Cuando un viento trae consigo un aire que es más frío que el cuerpo humano, entonces enfría. Si el aire aportado es más caliente que el cuerpo humano, entonces calienta, tanto más cuanto más rápido se mueve" ${ }^{36}$. La tabla 4 resume los vientos descritos por Kant en este apartado de su Geografía Física.

Tabla 4. Vientos regionales analizados por Kant en su Geografía Física.

\begin{tabular}{|c|l|}
\hline VIENTO y ÁREA AFECTADA & \multicolumn{1}{|c|}{ CARACTERÍSTICAS } \\
\hline Chamsin (Egipto) & Cálido, del desierto \\
\hline Samiel (Persia, Arabia y Siria) & Cálido, del desierto \\
\hline Terreno (Guinea) & Frío, procede de las montañas \\
\hline Norte (México) & Frío \\
\hline "Tornado" (Océano Índico y Etiópico) & $\begin{array}{l}\text { Húmedo, inestable. Sopla media } \\
\text { hora }\end{array}$ \\
\hline "Travado"37 (Océano Índico y Etiópico) & $\begin{array}{l}\text { Húmedo, inestable. Sopla varias } \\
\text { horas o días. }\end{array}$ \\
\hline Tornado (Sierra Leona) & Húmedo, inestable \\
\hline Ouragan (Golfo de México) & Húmedo, inestable \\
\hline Tifón (Mar de la China y de Japón) & Húmedo, inestable \\
\hline $\begin{array}{c}\text { Noreste y Suroeste (Islas Filipinas, Nueva } \\
\text { Cartagena) }\end{array}$ & Alisios, húmedos. \\
\hline
\end{tabular}

Fuente: Elaboración propia

Lo cierto es que este apartado de explicación de los vientos regionales viene a ser una caracterización de los "tipos de tiempo" que tienen lugar en diferentes áreas de la superficie terrestre, en relación con el viento que sopla en ellas. Kant, siguiendo la tradición hipocrática, otorga importancia a la cuestión de la salubridad o insalubridad de los vientos, puesto que este este carácter termina por otorgar condición al territorio que afecta.

Es interesante la explicación que Kant aporta sobre el viento "ouragan" y que viene a ser, en realidad, una descripción del fenómeno meteorológico de los ciclones tropicales. Kant señala que el viento huracán transporta nubes "que presentan aspecto de pompas" (cumulonimbos) y que tienen un color "horrible" 38 . Es curioso el detalle que señala sobre la estructura interna de de este mecanismo meteorológico del ámbito intertropical, puesto que habla de tres partes en el mismo: una con vientos del sudeste,

\footnotetext{
${ }^{36}$ Vid. op. cit. supra. Nota 14. §65.

${ }^{37}$ El término "travado" debe proceder del vocablo portugués "travado", que significa "intrincado", alusivo al carácter racheado, cambiante de un viento de tormenta. Los navegantes portugueses conocían bien la región del Índico desde finales del siglo XV.

${ }^{38}$ Vid. op. cit. supra. Nota 14. §65.
} 
otra de calma, y una tercera con vientos del sudoeste. Esta estructura en forma de "chimenea" de un ciclón tropical, con una explicación distinta de su génesis, es la que se sigue manejando en la explicación de este fenómeno atmosférico. Hay un error, sin embargo, a la hora de describir los "tifones" de los mares de la China y Japón, puesto que Kant indica que este meteoro "se establece en un lugar y no se propaga" 39 , aspecto no cierto, puesto que se trata de estructuras ciclónicas que se desplazan en el seno del flujo de los alisios de las latitudes intertropicales. Por el contrario, hay una precisión interesante en la explicación de estos "vientos" de tifón, común a todas las estructuras del tipo ciclón tropical del ámbito intertropical y es el efecto que tienen sobre el mar con la aparición de las denominadas "mareas de ciclón" debidas al oleaje originado por el viento que acompaña a este fenómeno meteorológico. Kant afirma que los tifones "acostumbran a formarse de los vapores expulsados con violencia por el mar; en tales casos el mar burbujea y hierve a borbotones en el lugar" ${ }^{\text {"40 }}$. Y apunta otro dato de importancia: los tifones pueden formarse en cualquier momento del año, no sólo en verano, en esta parte del mundo y ello porque incluso en invierno "el mar de la China es más cálido que los colindantes" ${ }^{41}$. Recordemos que la temperatura del agua del mar por encima de $28^{\circ} \mathrm{C}$ es una condición necesaria, como se sabe, para la formación y mantenimiento de estas estructuras meteorológicas tropicales.

Kant dedica unas breves líneas de su Geografía Física a caracterizar los vientos según la velocidad de los mismos. Como se ha señalado no se aportan datos de registro anemométrico, pero se indica el recorrido del viento en virtud de su categoría. Un viento suave "no se mueve más deprisa que una persona"42, uno más fuerte "se mueve como un caballo al galope"; un viento de tormenta "que arranca árboles" recorre " 24 pies por segundo ${ }^{43}$ "; por ultimo hay grandes tormentas en las que el viento recorre " 60 pies por segundo ${ }^{44,}$. Este tipo de comparaciones, serán utilizadas en las representaciones primeras de la escala de Beaufort (1806), incluidas en manuales de climatología del siglo XIX y comienzos del XX (Gil Olcina y Olcina Cantos, 1997).

Pero, sin duda, el apartado más destacado dentro del análisis del viento en la Geografía Física es el que hace alusión a la explicación de los vientos alisios ("Tradewinds").

Kant acepta esta denominación pero no explica su origen ${ }^{45}$ y señala que la causa de que entre los trópicos sople "un viento Este" de forma casi permanente es térmica:

${ }^{39}$ Vid. op. cit. supra. Nota 14. $\S 65$.

${ }^{40}$ Vid. op. cit. supra. Nota $14 . \S 65$.

${ }^{41}$ Vid. op. cit. supra. Nota $14 . \S 65$

${ }^{42}$ Vid. op. cit. supra. Nota 14. §66.

${ }^{43}$ Aprox. $7,3 \mathrm{~m} / \mathrm{s}$

${ }_{44}$ Aprox. $18,3 \mathrm{~m} / \mathrm{s}$

45 Pelowski (2004) señala que la expresión "trade-winds" no significaría, como se entiende habitualmente, "viento del comercio" en referencia a los vientos del ámbito intertropical que ayudaban a los veleros a desplazarse desde Europa al Nuevo Mundo en su travesía por el Océano Atlántico, sino que hace proceder el vocablo "trade" del verbo "tread" que se traduce 
"Éste -viento- no se origina a partir del aire que se retrasa, el que, como la Tierra gira de la tarde a la mañana, queda retrasado y resiste en la dirección opuesta, sino del calentamiento progresivo del día a la tarde por el Sol alrededor de la Tierra" ${ }^{46}$.

En esta explicación, Kant recupera el primer principio sobre el soplo del viento que había señalado en apartados anteriores (vid. supra) según el cual el viento se desplaza desde las zonas más frías a las más cálidas. De manera que en el ámbito intertropical el viento que se desplaza hacia el sur se desplazará siempre de Este a Oeste, siguiente el movimiento diario del Sol que irá calentando áreas situadas sucesivamente al Oeste. Y lo mismo para los vientos que en el Hemisferio Sur se desplazan hacia el Ecuador. Este principio, indica Kant, "es válido para todos los océanos que se encuentran entre los Trópicos: el Atlántico, Etiópico, Pacífico e Índico" ${ }^{47}$. Y añade que esta desviación de Este a Oeste es tanto mayor cuanto más grande es la distancia de su recorrido desde los trópicos hacia el Ecuador. Precisa el filósofo alemán que estos vientos pueden soplar más allá de los trópicos, pero "no mucho más allá de los treinta grados de latitud" 48 , aunque comenta el caso del "viento sur" que sopla en las costas de Chile y Perú y que no es sino el alisio que sopla en esa parte del Pacífico sur americano y que sigue la dirección de la línea de costa.

De manera que en la explicación de los vientos alisios, Kant atribuye su formación a causas exclusivamente térmicas, siguiendo el razonamiento presente en el escritos de Halley (1686), pero no el de origen termo-dinámico de Hadley (1735), aunque éstas últimas debía conocerlas, a la vista de la negación del efecto de la rotación en los vientos y el empleo del término "retraso" -aparente- de los mismos que se contiene en esta parte de su Geografía Física.

Kant anuncia una cuestión, no conocida en su época pero enormemente significativa; al referirse al soplo del alisio en la costa de Guinea señala que allí el alisio es del Oeste, en lugar de tener una componente de viento del Este, y explica que ello se debe a que el aire "se calienta más sobre Guinea que sobre el mar" fondo está ofreciendo una explicación a la zona de "doldrums" con predominio de vientos de componente occidental existente en las proximidades de la línea ecuatorial.

El mismo origen térmico es el que permite a Kant explicar, como se ha señalado, el funcionamiento de los vientos de mar y tierra (brisas). Aquí se alternan los dos primeros principios generales que Kant había señalado para el soplo del viento. La brisa de mar a tierra tiene que ver con el mayor calentamiento diurno de la superficie

por "pisar" o "hacer sendero". Por su parte, el vocablo francés "alizés" que se emplea para denominar a los vientos alisios significaría "estar unido", "ser plano o liso". No obstante, en el siglo XVIII, tanto en la Cyclopaedia (Londrés, 1728) como en la Enciclopedia Britannica (Edimburgo, 1771), la explicación de los vientos alisios maneja la expresión "trade-winds" en la acepción más comunmente aceptada de "vientos del comercio".

${ }^{46}$ Vid. op. cit. supra. Nota 14. $\$ 67$.

${ }^{47}$ Vid. op. cit. supra. Nota 14. §67.

${ }^{48}$ Vid. op. cit. supra. Nota 14. § 67.

${ }^{49}$ Vid. op. cit. supra. Nota 14. § 67. 
terrestre que favorece el movimiento del aire desde las zonas más frías (mar) hacia tierra. Por su parte, la explicación del terral o brisa de tierra se relaciona con el segundo principio general del viento, es decir, aquél según el cual si una zona se enfría poco a poco, el aire situado sobre ella se contrae y deja espacio para que sea ocupado por aire cálido; esto es lo que ocurre por la tarde y noche, según explica Kant -erróneamente- con el mar, que se enfría mucho antes que la superficie terrestre obligando a contraerse al aire situado sobre él y, de este modo, permite que el aire de tierra, más caliente, ocupe ese espacio generando así un flujo desde la tierra hacia el $\operatorname{mar}^{50}$. Es una explicación errónea del mecanismo de las brisas puesto que no tiene en cuenta el mayor calor específico del agua del mar que tarda en calentarse y enfriarse el doble de tiempo que una superficie continental. De manera que al no incluir la presión atmosférica como elemento clave, en la aparición de los flujos de brisa de mar y tierra, tal y como haría Vilhelm Bjerknes ${ }^{51}$ a comienzos del siglo XX (Medina Isabel, 1976), no encuentra una explicación satisfactoria en la el texto de Kant.

Otro apartado importante de la Geografía Física de Kant es el dedicado a la explicación de los vientos monzones o "vientos periódicos",52. A través de varias páginas de su obra, el filósofo explica la causa del soplo de estos vientos cambiantes a lo largo del año y que soplan en los mares de todo el cinturón cálido. Pero Kant va más allá e indica que esta explicación sirve de "teoría general de todos los vientos permanente, periódicos y de la mayoría de los cambiantes" ${ }^{, 53}$. De manera que resulta un tanto llamativo que manifieste esta intención casi al final del apartado dedicado a los vientos de su manual, cuando algunos apartados antes ya había señalado la causa, según él, del soplo de los "trade-winds". Y resulta, también, contradictorio, puesto que en este nuevo apartado dedicado a los monzones, la explicación causal de los mismo, difiere un tanto de la dada para los vientos alisios, al incorporar, ahora sí, la influencia de la rotación terrestre. En realidad, Kant, nos propone en este épigrafe de su tratado una serie de principios o razonamientos generales sobre el movimiento de los vientos en la superficie terrestre y su relación con la mencionada rotación terrestre, aunque sin abandonar ni mucho menos la causa térmica como origen primero del funcionamiento de la dinámica atmosférica general.

\footnotetext{
${ }^{50}$ Vid. op. cit. supra. Nota 14. $\$ 68$.

${ }^{51}$ El primer teorema de la circulación del aire de Vilheim Bjerknes señala que "si los gradientes de presión y de temperatura tienen direcciones distintas, se crea energía que fuerza al aire a circular en el sentido que lleva desde el extremo del vector gradiente de presión al del vector gradiente de temperatura, por el camino más corto". La explicación del circuito de brisas (diurna y nocturna) encuentra explicación satisfactoria en este principio. Estos principios están recogidos en las obras de V. Bjerknes "Das dynamische Prinzip der Zirkulationsbewegungen in der Atmosphäre". Meteorologiste Zeitschrift. 17, (1900), pp. 97106, 45-56.; y “" Zirkulation relativ zu der Erde," Meteorologische Zeitschrift 19 (1902): $97-$ 108. (Vid. Medina Isabel, 1976, pp. 13-19).

${ }_{52}^{5}$ Vid. op. cit. supra. Nota 14. § 68.

${ }^{53}$ Vid. op. cit. supra. Nota 14. § 70.
} 
En efecto, Kant, afirma que "como la Tierra rota alrededor de su eje, las partes de su superficie describen mayores paralelos, cuanto más cerca se encuentran del Ecuador, y más pequeños cuanto más cerca del Polo se encuentran, y el aire que cubre la Tierra sufre en todas partes, en ausencia de viento, el mismo movimiento que los elementos de la superficie de la Tierra, sobre los que se mueve. Por lo tanto, el aire del Ecuador se mueve del poniente hacia el levante con mayor velocidad, que el que se encuentra entre los Trópicos y éste más deprisa que el que se haya entre los círculos polares" 54 .

Y para explicar la formación de los vientos que se aproximan desde latitudes medias o subtropicales hacia el Ecuador, añade, "pero salido de tales zonas de la tierra -latitudes medias o subtropicales- donde por causa de los pequeños paralelos en los que se encontraba tenía poca velocidad del poniente al levante, como los elementos de la superficie de la Tierra, que se encuentran más próximos al ecuador y hacia los cuales se mueve, así será retrasado, porque no tiene un movimiento tan fuerte de Oeste a Este, lo que unido a la dirección Norte produce en nuestro hemisferio un viento Noreste, será tanto más viento Norte cuando más se aproxime al Ecuador, desviado en un viento Noreste. Y en el hemisferio Sur será un viento Sur transformado en uno Sudeste por los mismos motivos"

La tabla adjunta (vid. Tabla 5) resume los 3 principios básicos de circulación de vientos sobre la superficie terrestre, según Kant, y el giro que experimentan en relación con la velocidad de rotación de la Tierra en cada ámbito latitudinal.

A estos principios se une la ley general que explicaría el movimiento de los vientos de forma genérica y que se contiene, como se ha indicado, al inicio de la sección "Atmósfera" de la Geografía Física (vid. supra), según la cual el viento sopla siempre de los sectores fríos a los cálidos para compensar la menor densidad y el carácter lábil del aire situado sobre áreas con una mayor temperatura. Con ello y con los tres principios básicos de dinámica atmosférica que ahora añade en su obra, Kant nos propone su explcación de los vientos "monzones" que resultarían de la combinación de los principios $\mathrm{n}^{\mathrm{o}} 2$ y 3 . Vuelve, de este modo, el filósofo de Koningsberg a presentar un nuevo intento de explicación de los "monzones" que realmente sirve como explicación, asimismo, de los vientos alisios, ahora teñida con las ideas sobre los "trade winds" que Hadley había propuesto en su famoso, pero poco seguido en su época, artículo sobre el mecanismo de los vientos alisios publicado en la revista Philosophical Transactions, en 1735.

\footnotetext{
${ }^{54}$ Vid. Kant, I. Physical Geography [Rink's edition, 1802]. Vol. I, First part; Third section. § 70 (In. Watkins, E. (edit.) (2012) op. cit. supra. Nota 2).

${ }^{55}$ Vid. Kant, I. Physical Geography [Rink's edition, 1802]. Vol. I, First part; Third section. $\S$ 70 (In. Watkins, E. (edit.) (2012) op. cit. supra. Nota 2).
} 
Tabla 5. Principios de circulación de vientos propuestos por Kant en su Geografía Física.

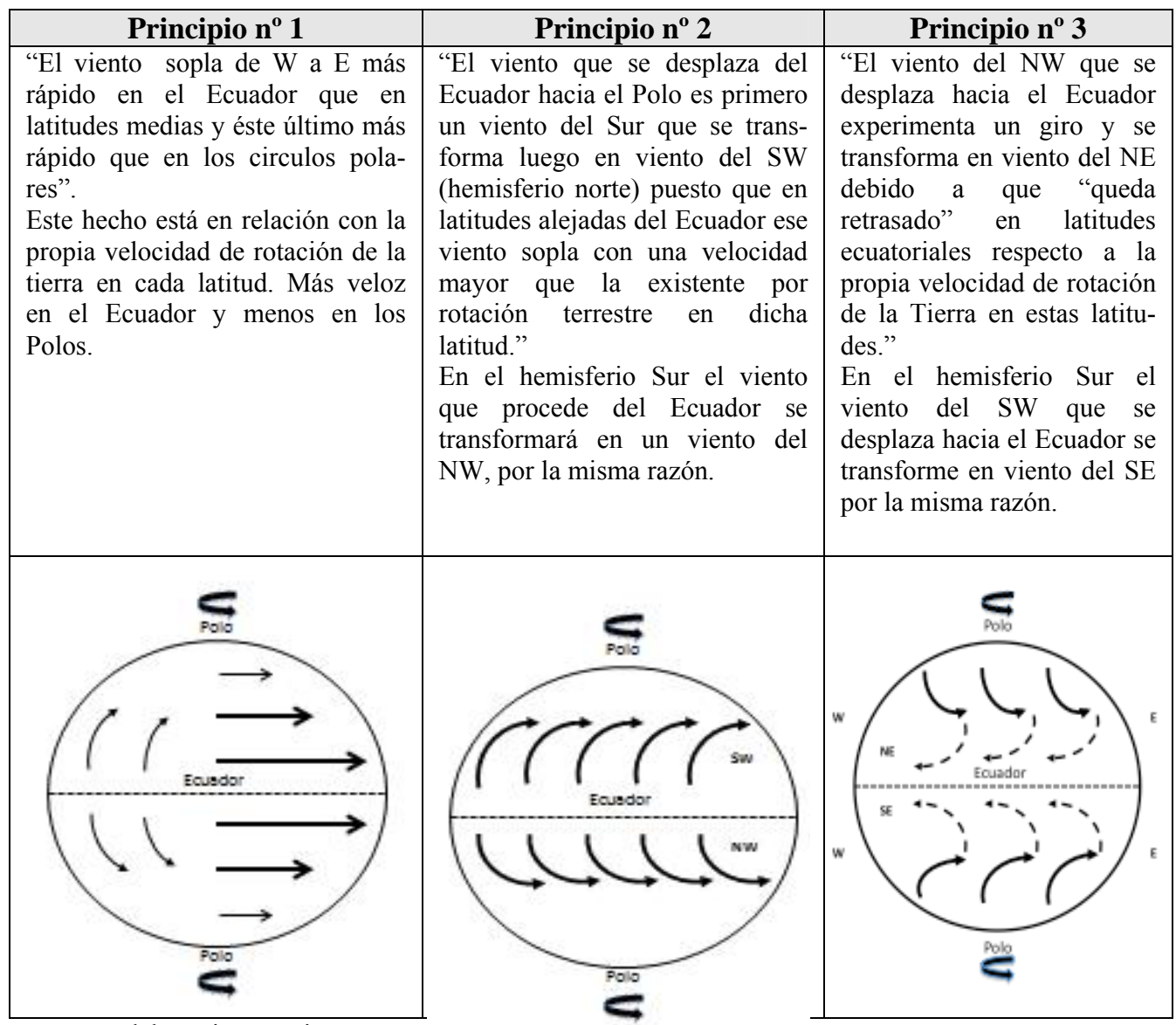

Fuente: Elaboración propia

Realmente la descripción del mecanismo de los monzones ocupa apenas un párrafo, pocas líneas después de la descripción de estos principios o razonamientos sobre el funcionamiento de la dinámica atmosférica. Y en esta descripción del funcionamiento de los vientos monzones, Kant retoma el principio "térmico" como causa exclusiva de los mismos: el mayor calentamiento de la superficie terrestre en el área continental del sur de Asia entre marzo y septiembre origina que el viento del océano Índico se desplace hacia el continente con una trayectoria Sudoeste. "Esto, añade Kant, ocurre en el hemisferio sur, sólo en los meses restantes de forma que el 
aire del hemisterio norte será desplazado hasta aquí y producirá un viento Noroeste"56. Así se explica el circuito estacional de los monzones. En los períodos de alternancia entre una circulación (verano) y otra (invierno), en cada hemisferio, "predominarán calmas y huracanes" ${ }^{\prime 57}$. Se trata de una apreciación certera porque, en efecto, los ciclones tropicales en esta parte del mundo -Sur de Asia y océano Índico- tienen lugar en los "equinoccios" de primavera y otoño, frente a otras zonas del mundo afectadas por este fenómeno meteorológico - p.e. Caribe- donde se desarrollan sólo en un único período anual, entre finales del verano y comienzos del otoño.

La figura adjunta (vid. Figura 4) presenta la propuesta de explicación causal de los monzones, en el hemisferio norte, que se recoge en la obra del filósofo alemán.

Figura 4. Explicación de los monzones según Kant en su Geografía Física.

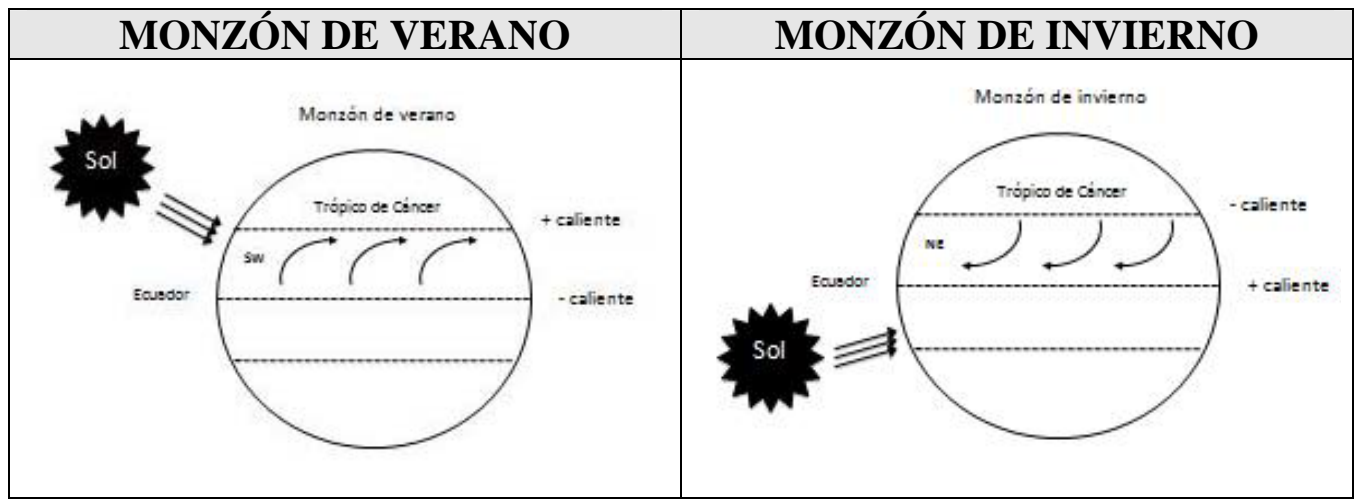

Fuente: Elaboración propia

Un último apartado dedicado al viento, dentro de la Geografía Física de Kant amplia estas ideas sobre el movimiento de los vientos que tan interesantes resultan en la obra del filósofo. En efecto, en el apartado titulado "Algunas otras leyes sobre la alternancia de los vientos", Kant nos propone una explicación sobre la circulación de los vientos en latitudes medias, que avanza lo que años más tarde, Dove formularía como "ley del giro" (1827). En efecto, afirma Kant que "en nuestro hemisferio norte los vientos acostumbran, cuando se mueven del Norte al Noreste, a finalizar todos los giros de izquierda a derecha, a saber Este, Sur y Oeste", y añade" sólo los vientos de de un modo opuesto se mueven del Norte al Oeste, no acostumbran jamás a recorrer

${ }^{56}$ Vid. op. cit. supra. Nota $14 . \S 70$.
${ }^{57}$ Vid. op. cit. supra. Nota $14 . \S 70$. 
el círculo entero" ${ }^{\$ 5}$. Y en el hemisferio sur a la inversa dado que "el recorrido del Sol es de derecha a izquierda, como ha constatado Don Ulloa en el Pacífico"s9

Figura 5. Esquema de circulación de vientos, según zonas térmicas del planeta, en la Geografía Física de Kant.

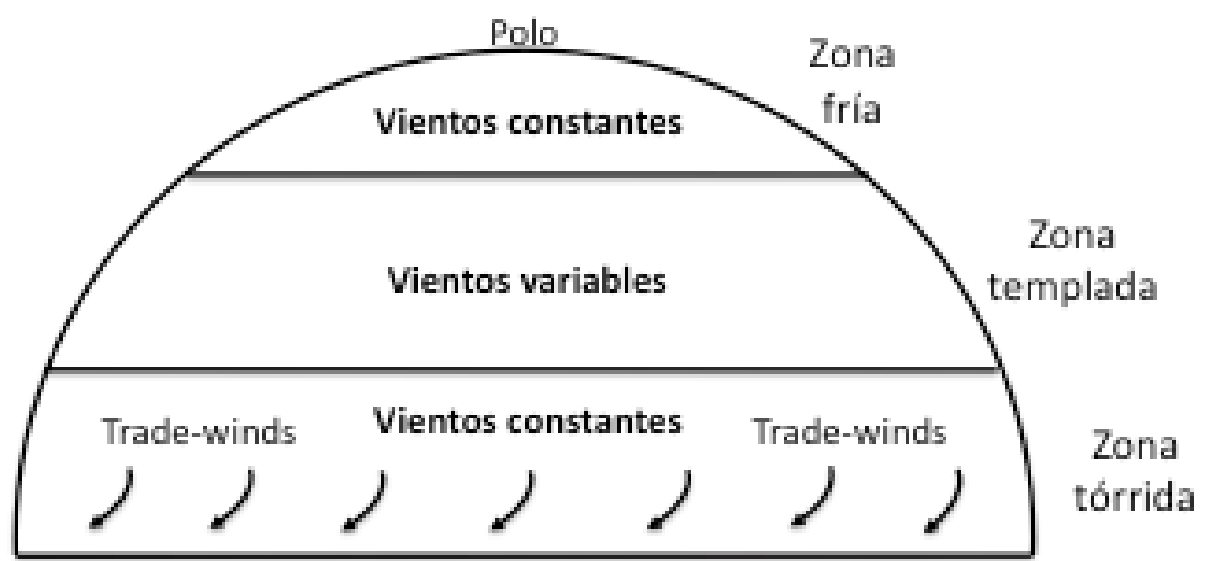

\section{Ecuador}

Fuente: Elaboración propia

Kant hace responsable último de este movimiento al Sol: "el recorrido del Sol, señala, desvía de una manera natural el viento Norte en otro Noreste; sólo si se le resiste el viento del Sur será completamente del Este; entonces empieza el viento del Sur a regresar y por su combinación con el viento del Este se hace Sudeste, después completamente del Sur, entonces Sudoeste y si existe resistencia del aire del Norte completamente del Oeste" ${ }^{" 60}$. Años más tarde, Dove incluirá en la explicación del giro del viento a la rotación terrestre, que resulta básica para poder entender el movimiento del aire que se desplaza latitudinalmente ${ }^{61}$ (Carramolino, 1994).

En este apartado, hay, por último, una propuesta de "esquema de circulación atmosférica general", aunque Kant no lo propone como tal ni, por supuesto, lo dibuja

\footnotetext{
${ }^{58}$ Vid. op. cit. supra. Nota 14. $\S 71$.

${ }^{59}$ Se trata de Antonio de Ulloa cuya obra conocía Kant, como se ha señalado (vid. supra) y fue utilizada como bibliografía de consulta en sus apuntes de Geografía Física.

${ }^{60}$ Vid. op. cit. supra. Nota 14. § 71.

${ }^{61}$ Dove no conocerá hasta 1846 la explicación del giro de los vientos incluida en la Geografía Física de Kant, por lo que no pudo tenerla en cuenta en la formulación inicial de su "ley del Giro" en 1827.
} 
en su obra" ${ }^{62}$. En efecto, afirma Kant que "los vientos son más variables enla mitad entre un polo y el Ecuador. Tanto en la zona cálida y regiones adyacentes como en el cinturón frío y zonas vecinas son mucho más constantes"63 (vid. Figura 5). Y termina señalando los cambios en el viento originados en una columna atmosférica, que pueden llegar a provocar "calmas y tormentas repentinamente o viento cambiante en los territorios bajos". Este último es un aspecto de gran interés porque inaugura la serie de estudios sobre el espesor de las capas atmosféricas que tendrán en la navegación aerostática un hito principal, aunque será en el siglo XX, con el desarrollo de la aviación y, posteriormente, de los satélites de finalidad meteorológica, cuando adquiera su completa y detallada explicación.

\section{c) Temperaturas}

Frente al extenso apartado que dedica Kant, en su Geografía Física, a describir y explicar el elemento climático del viento, el resto de elementos merecen un espacio mucho menor en su obra ${ }^{64}$. Kant dedica unos párrafos de su obra a analizar la relación entre tiempo, clima y las estaciones del año ${ }^{65}$. Hace constar el efecto de templanza de las aguas del mar en las temperaturas de las zonas costeras; por el contrario, indica el carácter más duro del clima de las tierras de interior a consecuencia de la continentalidad. Y ello lo ilustra el filósofo con ejemplos de localidades de costa e interior de Noruega ${ }^{66}$. Y afirma que en las tierras orientales (China) debido a la gran extensión continental los inviernos llegan a ser más duros que incluso en tierras situadas en latitudes más septentrionales: "En Norte América, señala Kant, a la latitud de Francia, los inviernos son más duros que en el norte de Suecia" ${ }^{, 67}$.

Kant señala que el hemisferio Sur es más frío que el Norte y apunta como causa de ello la propia existencia de una gran masa de hielo flotante que existe en latitudes australes: "El hemisferio sur es más frío que el norte a la misma latitud. En el centro

${ }^{62}$ Uno de los problemas de la Geografía Física de Kant es que no se incluye ninguna ilustración o dibujo de sus propuestas de explicación de los fenómenos atmosféricos, aunque no parece extraño que los utilizara en sus clases.

${ }^{63}$ Vid. op. cit. supra. Nota 14. $\S 71$.

${ }^{64} \mathrm{El}$ análisis del resto de elementos climáticos y de otros meteoros dentro de la Geografía Física de Kant está más completo en la edición de Vollmer (1801) que en el manuscrito de Rink (1802), de ahí la necesidad de complementar la lectura del segundo, manejado básicamente en este estudio, con los volúmenes publicados por Augusto Eckerlin del manuscrito de Vollmer, en la edición italiana de la obra (vid. supra. apartado 3).

${ }^{65}$ Vid. Kant, E. Geografia Física. (Edición de Augusto Eckerlin) Tradotta dal tedesco. Vol. Sesto. Milano, 1811. Dalla Tipografia di Giovanni Silvestri. III Capitolo della Prima Parte. Seconda Sezione. Divisione Terza, Págs. 177-185.

${ }^{66}$ Vid. op. cit. supra. Nota 14. $§ 73$.

${ }^{67}$ Vid. op. cit. supra. Nota 14. § 73. 
del verano, a la latitud de Inglaterra, debido a la presencia grandes bloques de hielo que nunca se derriten flotando en el mar"68.

Y va más allá en sus apreciaciones sobre la temperatura de la superficie terrestre al comparar las temperaturas registradas en su época con tiempos anteriores. Kant afirmar que en "otros tiempos" Europa era más fría que en la actualidad y para ello señala el caso del Ródano helado en tiempos de Julio César o del mar Negro helado en época de Constantino. Y llega a indicar que "Alemania a lo largo del Rin y Francia son descritas, por los antiguos, como similares a Siberia hoy"69 (vid. infra.). Es una apreciación curiosa la del filósofo alemán, cuya vida transcurre en el tramo final de la Pequeña Edad del Hielo (PEH), que justifica señalando como causa la existencia de mayor superficie forestal entonces, frente a la existente en su época. Y ello contribuiría, según Kant, "a mantener más el frío y a favorecer el soplo de vientos más fríos sobre estas masas boscosas" ${ }^{70}$. Se lamenta Kant de la deforestación practicada en Europa que habría templado el clima, en comparación con los rasgos climáticos existentes en Norte América o Asia donde la existencia de grandes extensiones de bosque haría sus climas muy más fríos, como ocurre, especialmente "en China y Siberia"

Señala Kant que en la zona tórrida "el invierno se produce, actualmente, en los meses de verano" y sólo consiste en un período de lluvia, "cuando el Sol está realmente cercano a ellos -en el horizonte-, justo en ese momento hay un aire muy bochornoso"72. Y apunta que el resto del año es denominado "estación seca "o "buena estación". Insiste en el mayor "rigor" térmico estival en la zona tórrida del hemisferio Sur y lo atribuye Kant a la existencia, apuntada, de grandes masas de hielo en el Polo sur.

\section{d) Otros meteoros}

Kant realiza, por último, una descripción de diferentes meteoros conocidos y para ello parte de una división básica entre meteoros húmedos (hidrometeoros), meteoros ígneos (meteoros eléctricos) y meteoros ópticos ${ }^{73}$.

Entre los primeros describe el rocío, la helada, la niebla, las nubes, la lluvia, la nieve y el granizo. Hay algunas cuestiones curiosas en este apartado que interesa destacar. Así, en la explicación del rocío hace constar la importancia que este meteoro tiene para las plantas y recoge en su escrito Kant la existencia de una obra, consultada

\footnotetext{
${ }^{68}$ Vid. op. cit. supra. Nota 14. $§ 73$.

${ }^{69}$ Vid. op. cit. supra. Nota 14. § 73.

${ }^{70}$ Vid. op. cit. supra. Nota 14. § 73.

${ }^{71}$ Vid. op. cit. supra. Nota 14. § 73.

${ }^{72}$ Es la explicación de lo que los climatólogos franceses, desde De Martonne, denominarán hivernage al describir el tiempo atmosférico característico de la estación lluviosa de verano (De Martonne, 1964, p. 251).

${ }^{73}$ Vid. op. cit. supra. Nota 65. Págs. 70 a 176.
} 
por él, del físico francés Charles François de Cisternay du Fay (1698-1739) sobre la importancia de la transmisión eléctrica en el rocío ${ }^{74}$. Para explicar la niebla y el espesor que en ocasiones alcanza este hidrometeoro el filósofo alemán acude a la anécdota del paso de una carroza por la ciudad de Hamburgo, ocurrido el 8 de noviembre de 1775 , cuyo conductor encontró una niebla tan densa que apenas "se podía ver a 4 pasos" y tuvo que esperar dos horas para poder desplazarse al puerto de la ciudad, "cuando la niebla levantó y comenzó a lucir un sol resplandeciente ${ }^{75}$ ". Kant describe varios ejemplos de localidades afectadas por este fenómeno meteorológico y hace constar el cambio térmico que se produce en el interior de una zona de nieblas, donde las temperaturas resultan "más frías que en el exterior".

Define las nubes como "nieblas de una región muy alta" y hace mención, para justificar esta definición, a que en la expedición americana para la medición del arco de meridiano el astrónomo y matemático francés Pierre Bouguer encontró nubes "en la cima del Chimborazo a 700-800 toesas" ${ }^{, 76}$. Aunque no será hasta comienzos del s. XIX cuando el farmacéutico inglés Luke Howard esboce la clasificación de nubes que haría fortuna y sería asumida por la Organización Meteorológica Internacional en su Atlas Internacional de Nubes, Kant ofrece unas consideraciones interesantes sobre este hidrometeoro. Así, señala que el color de las nubes "depende de la reflexión de los rayos del Sol sobre ellas" y hace mención a la electricidad que se mueve en determinados géneros de nubes: "las nubes más altas contienen mucha electricidad"77. Todo ello en la época en la que Benjamin Franklin estaba desarrollando sus ideas sobre la electricidad atmosférica ${ }^{78}$.

En el apartado dedicado a explicar la lluvia, Kant aporta algunos datos de precipitación anual (medidos en pulgadas) de diferentes ciudades de los Países Bajos (Utrecht, Leyden, Harlem, La Haya, Delft, Dordrecht, Middelburg y Hardewijk) ${ }^{79}$, para una media de siete años ${ }^{80}$, lo que muestra que, en su época, ya funcionaba la observación meteorológica diaria organizada, incluso, en redes de observación dentro

\footnotetext{
${ }^{74}$ El físico y químico francés du Fay, siguiendo los trabajos del inglés Stephen Gray fue el primero en identificar la existencia de dos tipos de cargas eléctricas en los cuerpos, que denominó carga vítrea y carga resinosa. Su trabajo fue publicado en la prestigiosa revista Philosophical Transactions (1734).

${ }^{75}$ Vid. op. cit. supra. Nota 65. Págs. 70 a 176. p. 81-82.

${ }^{76}$ La toesa francesa equivalía a 1,9490 metros, equiparable a 6 pies o 72 pulgadas.

${ }_{77}$ Vid. op. cit. supra. Nota 65. Págs. 70 a 176. Págs. 83-84.

${ }^{78}$ Durante una estancia en Francia, en 1752, Benjamin Franklin llevaría a cabo el famoso experimento de la cometa, que le permitió demostrar que las nubes están cargadas de electricidad y que, por lo tanto, los rayos son esencialmente descargas de tipo eléctrico.

${ }_{79}$ Algunas de estas estaciones meteorológicas formarían parte de la red meteorológica europea de la Sociedad Meteorológica Palatina, de Manheim, patrocinada por Príncipe elector Kart Theodor del Palatinado, que mantuvo una red de observación entre los años 1780 a 1795 y publicó una importante serie de datos. La red llegó a estar formada por 39 estaciones que integraban ciudades desde Groenlandia hasta Roma y desde La Rochelle a Moscú, algunas de las cuales ya venían realizando observaciones desde hacía tiempo.

${ }^{80}$ Vid. op. cit. supra. Nota 65. Págs. 70 a 176. Pág. 89.
} 
de algunos territorios europeos (Brazdil et alt., 2005). Kant realiza en este apartado de su Geografía Física una caracterización singular de tipos de precipitación a las que intenta dar explicación causal y presenta con ejemplos de episodios conocidos por él, por referencias indirectas. Esta clasificación de lluvias incluye las lluvias "de leche", las lluvias "de sangre", las lluvias "de gusanos", las lluvias "de ranas" y las lluvias "de piedras (volcánicas)" $"$. Entre otros eventos, comenta un suceso de una lluvia de sangre ocurrida en 1711 en Escania y Kant atribuye dicha coloración de la lluvia al transporte que harían los insectos de pigmentos de esa coloración procedentes de flores. No podía imaginar el filósofo alemán que esa coloración procediera del polvo sahariano que, en ocasiones, alcanza latitudes europeas tan septentrionales.

Por último, explica Kant la nieve y el granizo; de este último hidrometeoro señala, aunque desacertadamente, que "no cae en invierno" ${ }^{2}$, afirmación que puede ser válida, con matices, para el ámbito del norte de Europa donde residía el filósofo, pero no para latitudes medias más meridionales donde la precipitación en forma de granizo, de tamaño diverso, puede caer también en meses invernales.

En la sección dedicada a los "meteoros ígneos" incluye Kant la descripción de una serie de fenómenos eléctricos o electrometeoros de los que aporta datos interesantes. Al describir los rayos que se forman en las nubes de tormenta hace mención a los trabajos de Johann Winkler y Benjamin Franklin sobre electricidad y se refiere, en concreto, al pararrayos recomendado por este último para evitar los efectos de este fenómeno eléctrico ${ }^{83}$. Kant incluye en este apartado el relato de una anécdota referida a la experiencia llevada a cabo por un eclesiástico en Moravia que, para defenderse de las nubes de tormenta, tocaba las campanas de su iglesia, aunque, -señala el filósofo-, esta acción no tenía ningún efecto ${ }^{84}$. Describe, asimismo, el llamado "fuego de San Telmo", el fenómeno de los "bolos" (rayo globular), de las "auroras boreales" y del "fuego fatuo". Sobre las auroras boreales hace constar un evento intenso de auroras boreales observado en 1787 en Ronnenburg y otro en Unleaburg ocurrido en $1791^{85}$.

Se incluye, finalmente, en este apartado de la Geografía Física, una descripción de "meteoros ópticos" o fotometeoros donde se describe el "arco iris", la "fata morgana", los "parhelios y parselenes", la "corona solar" y el "alba y el crepúsculo" Kant el acontecimiento de "fuego fatuo" observado por Bouguer, Godin y La Condomine en la montaña Pambamarca en 1736, durante la mencionada expedición americana para la medición del arco de meridiano ${ }^{87}$. Y resulta interesante la definición que ofrece Kant sobre dos estos últimos fenómenos ópticos, que en realidad hacen alusión al mismo fenómeno óptico (crepúsculo) con sus variantes

\footnotetext{
${ }^{81}$ Vid. op. cit. supra. Nota 65. Págs. 70 a 176. Págs. 92-110.

${ }^{82}$ Vid. op. cit. supra. Nota 65. Págs. 70 a 176. Págs. 110-117.

${ }^{83}$ Vid. op. cit. supra. Nota 65. Págs. 70 a 176. Págs. 113-114.

${ }^{84}$ Vid. op. cit. supra. Nota 65. Págs. 70 a 176. Págs. 127-128.

${ }^{85}$ Vid. op. cit. supra. Nota 65. Págs. 70 a 176. Págs. 137-139.

${ }^{86}$ Vid. op. cit. supra. Nota 65. Págs. 70 a 176. Págs. 165-176.

${ }^{87}$ Vid. op. cit. supra. Nota 65. Págs. 70 a 176. Págs. 168-169.
} 
diurna (alba) y nocturna (ocaso), y que "se producen cuando las nubes o la humedad reflejan sólo los rayos rojos durante el ascenso y descenso del Sol" ${ }^{\prime 88}$ respectivamente. Kant se aproxima, acertadamente, a la causa última de su formación explicada en la actualidad como una consecuencia elemental de la reflexión y difusión de la luz solar.

\section{e) Evolución del clima terrestre: ¿clima cálido en el final de la Pequeña Edad del Hielo?}

Hay un aspecto en la descripción de aspectos climáticos en la Geografía Física de Kant que resulta, cuanto menos, llamativo. En la sección cuarta de la obra, en la que se aborda la cuestión de la temperatura y su relación con la naturaleza y situación de un lugar Kant incluye unas deliciosas páginas sobre la historia del clima terrestre ${ }^{89}$. Kant reconoce que esta reconstrucción climática del pasado es una tarea difícil por la inexistencia de datos y aparatos de medición de la temperatura que permitiera hacer comparaciones con las temperaturas de su época. De manera que sólo los relatos de autores clásicos permiten hacerse una idea de las condiciones ambientales del pasado. En este repaso por algunas épocas históricas y sus condiciones climáticas señala que, en general, el período romano y bizantino fueron épocas más frías que las actuales, "con los ríos cubiertos de hielo"; al respecto indica que César condujo sus legiones "sobre el Ródano helado".

Como se ha señalado con anterioridad (vid. supra), resulta llamativo que Kant tenga la sensación, en plena fase final de la Pequeña Edad del Hielo de que el clima de su época, sea más frío que en épocas anteriores (p.e. período romano). Esta impresión la argumenta Kant a partir del relato de historiadores como Plinio el Viejo o Estrabón, cita expresamente en su Geografía Física: "en tiempo de Estrabón no tenían éxito ni los higos, ni el olivo ni la vid. El bosque y el humedal cubrían el suelo y en Germania habitaban fieras como alce y bisonte" ${ }^{0}$.

Kant hace mención a la existencia de unas condiciones climáticas más cálidas en Germania con anterioridad al tiempo de César, lo que habría favorecido la presencia de animales propios de estas condiciones climáticas más benignas, como elefantes, rinocerontes y osos de "especies singularísimas" se habría extendido, indica Kant, en las tierras de Suiza como atestigua el hallazgo de huesos de este tipo de animales.

Es llamativo, sin embargo, que Kant no se refiera a las condiciones de clima más benigno del Medievo y a la transcendencia que ello tuvo para las expediciones y colonización del Atlántico norte o que no aluda tampoco a las condiciones climáticas extraordinariamente frías que acompañaron al "minimo de Maunder", entre finales del s. XVII y comienzos del s. XVIII. Y no alude al tiempo especialmente alterado

\footnotetext{
${ }^{88}$ Vid. op. cit. supra. Nota 65. Págs. 70 a 176. Pág. 176.

${ }^{89}$ Vid. op. cit. supra. Nota 65. Págs. 70 a 176. Págs. 189-193.

${ }^{90}$ Vid. op. cit. supra. Nota 65. Págs. 70 a 176. Pág. 190.

${ }^{91}$ Vid. op. cit. supra. Nota 65. Págs. 70 a 176. Pág. 191.
} 
que vivió Europa en las décadas finales del s. XVIII, cuando el filósofo desarrolló su labor académica en la Universidad de Koningberg. Aunque es cierto que los años centrales del s. XVIII tuvieron un carácter térmico menos riguroso su comportamiento térmico en relación al resto de dicha centuria, no lo es menos el hecho de que las temperaturas medias en Europa fueron en este siglo significativamente más bajas que en otras épocas climáticas más cálidas (período romano, óptimo climático medieval). Y ello era especialmente contrastado en los crudos inviernos de esas décadas (Antón Uriarte, 2002).

Hay, por último, algunas afirmaciones del filósofo que resultan curiosas a la vista de los conocimientos actuales en climatología regional. Así, señala que el Nuevo Mundo es más frío que Europa y, como ya se ha apuntado con anterioridad (vid. supra) que el hemisferio Sur es más frío que el Norte $^{92}$. Se trata de afirmaciones condicionadas por la consulta de obras de la época con descripciones de las condiciones geográficas de localidades de América del Sur coronadas las imponentes altitudes de la cordillera Andina que habrían hecho presumir al filósofo de la existencia de unos rasgos climáticos más fríos (tierras altas) en buena parte del Nuevo Mundo y, que hace extensivos al conjunto del hemisferio Sur.

\section{A MODO DE CONCLUSIÓN: LA EVOLUCIÓN POSTERIOR DE LAS IDEAS CLIMÁTICAS DE KANT}

La Geografía Física de Kant reune, como se ha señalado, buena parte de los conocimientos geográficos existentes en la época ilustrada. Y aunque en la descripción de los diferentes territorios de la superficie terrestre no supone un avance epistemológico dentro de la evolución de la disciplina geográfica, si contiene en los capítulos de contenido general sobre el medio natural, explicaciones de fenómenos de la naturaleza que contribuyen a mejorar el nivel de conocimiento sobre estas cuestiones existentes hasta ese momento. Es el caso, como se ha señalado, de los aspectos meteorológicos y climáticos que se incluyen en sus páginas.

Kant resulta innovador para la época en sus explicaciones sobre el funcionamiento de los vientos en general y sobre el movimiento de dos circulaciones aéreas de desarrollo constante a lo largo del año, los vientos alisios y los monzones. Para ello propone tres principios básicos del movimiento del aire en la atmósfera, donde relaciona los principios térmicos con la rotación terrestre. Asimismo, explica el fenómeno de las brisas en las áreas costeras, aunque sin tener en cuenta la influencia, demostrada esencial, de la presión atmosférica, como fijaría $\mathrm{V}$. Bjerkness en su conocido "primer teorema" de la circulación de vientos, en el tránsito del siglo XIX al $\mathrm{XX}$. Mantiene la división -de época griega- en tres grandes zonas térmicas de la superficie terrestre, para cada hemisferio, que, en esencia, se maneja en la actualidad

${ }^{92}$ Vid. op. cit. supra. Nota 65. Págs. 70 a 176. Págs. 188-189. 
en los estudios de balance energético planetario. Y, asimismo, plantea la existencia de las tres capas atmosféricas que ya había explicado Aristóteles en su Meteorología (s. IV a.C), aspecto que sin embargo quedará superado con el progresivo descubrimiento y caracterización de las diferentes capas -y subcapas- atmosféricas que permitirá los vuelos aerostáticos, primero, y la navegación de los satélites de finalidad meteorológica, en la segunda mitad del siglo XX..

Se trata, en suma, de cuestiones que, recopiladas por Kant en su Geografía Física, se presentan por vez primera con apariencia de brevario o pequeño manual de climatología novedoso a finales del s. XVIII. No obstante, sus aportaciones serán revisadas y cuestionadas a la vista de los avances ocurridos en meteorología y climatología a lo largo de los siglos XIX y XX.

Resulta, sin embargo, sorprendente que el filosofo alemán no incluya en el apartado dedicado a la cuestiones atmosférica de esta obra, ni tampoco en ningún escrito elaborado por él sobre cuestiones de la naturaleza, una descripción de zonas o ámbitos climáticos de la superficie terrestre. Es cierto que se incluyen explicaciones sobre diferencias térmicas, pluviométricas y de soplo de vientos en regiones o localidades del mundo, pero no se llega a esbozar un intento de clasificación climática. Habrá que esperar casi un siglo, desde las lecciones universitarias de geografía de Kant, para encontrar una primera propuesta de clasificación de zonas térmicas del planeta, que será elaborada por A. Supan en 1879 y daría paso a un conjunto de clasificaciones climáticas algebraicas, basadas en el establecimiento de umbrales de temperatura y/o precipitación.

Las ideas sobre el movimiento del viento y la explicación de fenómenos atmosféricos relacionados con este elemento climático encontrarán explicación definitiva a lo largo de los siglo XIX y XX, merced a la mejora de los fundamentos de la física del aire y de la instrumentación de finalidad meteorológica. El factor térmico y sus diferencias espaciales dejará de ser la causa principal del movimiento del aire y adquirirá protagonismo la presión atmosférica y sus variaciones. Como ya adelantara Hadley en su propuesta de explicación de los vientos alisios (1735) la rotación terrestre se entenderá fundamental para justificar la encurvación del viento y no sólo en el ámbito intertropical. La ganancia o perdida de velocidad angular y las variaciones de tamaño de una columna de aire en relación con la velocidad lineal del viento existente en un área geográfica, permitirán explicar la formación de torbellinos puntuales, ciclones extratropicales, anticiclones dinámicos y desarrollos ciclogenéticos. Y la influencia decisiva de la circulación de las capas altas de la troposfera en los fenómenos meteorológicos de superficie, así como de las interacciones entre circulaciones oceánica sy atmosféricas se irá desarrollando a lo largo del siglo XX. Los trabajos de Coriolis, Ferrel, Brandes, Dove, Buys-Ballot, Hildebrandsson, van Bebber, Teisserenc de Bort, Abercromby, Bjerkness y los meteorólogos de ls Escuela de Bergen o de Rossby a lo largo de las dos últimas centurias, resultarán decisivos para el correcto conocimiento de la dinámica atmosférica terrestre (Gil Olcina y Olcina Cantos, 1997).

E igualmente sucede con sus propuestas sobre circulación atmosférica general y las diferentes zonas de afección de la misma en la superficie terrestre propuestas por 
el filósifo en la Geografía Física o en sus escritos sobre el viento, que irán encontrando explicación causal defintiva a partir de la segunda mitad del siglo XX con los descubrimientos de la circulación en capas altas atmosféricas (corrientes en chorro) y del movimiento del aire en el ámbito intertropical.

Por último, la reconstrucción histórica del clima terrestre que contiene la Geografía Física de Kant puede entenderse como el primer ensayo existente, como tal, de climatología histórica. Es cierto que las ideas que señala sobre el caracter bonancible del tiempo y clima en su època historica no resultan ciertas, a la vista de los conocimientos actuales sobre la evolución del clima terrestre, puesto que la segunda mitad del siglo XVIII, en la fase final de la Pequeña Edad del Hielo, resultó bastante inquieta en los atmosférico. Con todo, es la primera vez que un autor presenta un relato, con criterio cronológico, con indicación de diversas etapas o fases del clima terrestre. Habrá que esperar hasta la segunda mitad del s. XX, cuando los trabajos del historiador francés Le Roy Ladurie, discipulo aventajado de Fernand Braudel, inaugurarán, a partir de $1967^{93}$, una corriente de estudios históricos del clima que en la actualidad vive momentos de gran empuje (Alberola Romá, 2014).

Inmanuel Kant, el gran filósofo del idealismo alemán del siglo XVIII, es, también, una pieza básica en la evolución de la disciplina geográfica. Su obra no es un simple tránsito entre la geografía más "clasica" de Varenio y la más "científica" de Humboldt o Ritter. Su Geografía Física y el conjunto de escritos sobre cuestiones de la Naturaleza que nos ha legado contienen ideas e interpretaciones novedosas, herederas de un tiempo nuevo marcado por la física de Newton y la necesidad de encontrar explicación racional a los fenómenos.

Un profesor universitario que durante cuarenta años imparte lecciones de geografía debe considerarse, con pleno derecho, geógrafo. Y si esa trayectoria docente procede de una absoluta convicción intelectual de que la geografía, como disciplina que se ocupa del "espacio", es un aprendizaje básico para el ser humano dentro del sistema de coordenadas del conocimiento racional, su obra debe ocupar un lugar más destacado del que, por tradición, se le otorga en la explicación -lineal- de la evolución del pensamiento geográfico. Para el entendimiento de fenómenos meteorológicos y de procesos de circulación atmosférica este protagonismo es, sin duda, merecido.

${ }^{93}$ En 1967, Emmanuel Le Roy Ladurie, publicará su conocido y excelente ensayo "Histoire du climat depuis l'an mil” (Ed.Flammarion, 381 p) . 


\section{BIBLIOGRAFÍA}

ALBEROLA ROMÁ, A. (2014). Los cambios climáticos. La Pequeña Edad del Hielo en España, Madrid, Ed. Cátedra, 341 p.

ARCIMIS, A. (1902). Meteorología. Barcelona, Manuales Soler nº XVIII, 198 p.

BARRY, R. G. and CHORLEY, R. J. (1999) Atmosphere, Weather and Climate. (7 ed.), London and New York, Ed. Routledge, 441 p.

BELAVAL, Y. VON. (dir.) (1982). La filosofía alemana, de Leibniz a Hegel. Historia de la Filosofía. Mexico, Ed. Siglo XXI, 459 p.

BOROWSKI, L. E. (1993). Relato de la vida y el carácter de Immanuel Kant. Madrid, Tecnos.

BRAZDIL, R.CH.; PFISTER CH., WANNER H., VON STORCH, H. and LUTERBACHER, J. (2005). "Historical climatology in Europe. The state of the art", Climate Change 70, 363-430.

CAPEL, H. (2012). Filosofía y Ciencia en la Geografía contemporánea. Barcelona, Ediciones del Serbal, $480 \mathrm{p}$.

CARRAMOLINO, D. (1994). "La "Ley de Giro" (Drehungsgesetz) de Dove (1827) y el nacimiento de la dinámica atmosférica en Aemania". Endoxa: Series Filosóficas, $\mathrm{n}^{\circ} 3,95-119$.

CASSIRER, E. (1997). Kant, vida y doctrina. Bogotá, Fondo de Cultura Económica.

CASTRO-GÓMEZ, S. (2005). "Espacios estriados. Geografia, políticas del territorio y control poblacional”, en La Hybris del Punto Cero, Bogotá, Editorial Pontificia Javeriana, $76 \mathrm{p}$.

(Disponible en: http://www.ram-wan.net/restrepo/metodologia/hybris-cap5castro.pdf).

COHEN-HALIMI, M. (1999). "Le Géographe de Königsberg". In: KANT, Immanuel. Géographie. Physische Geographie. Paris, Aubier, p. 9-40.

COPLESTON, F. (2011). Historia de la Filosofía. Vol. 3. (De la Filosofía Kantiana al Idealismo). Barcelona, Ed. Ariel. Col. Filosofía, 752 p.

CHAMBERS, E. (1728) Cyclopaedia: Universal Dictionary of Arts and Sciences. Londres. (voz. "Trade-winds") (on-line: www.cyclopaedia.eu).

DESCARTES, R (2007). Discurso del método. Madrid. Ed. Akal, 96 p.

ELDEN, S. (2008). "Reassessing Kant's geography". Journal of Historical Geography (doi: 10.1016/j.jhg.2008.06.001).

ELDEN, S. (2011). Reintroducing Kant's geography. Albany, State University of New York Press, $15 \mathrm{p}$.

DE MARTONNE, E. (1964). Tratado de Geografía Física. Tomo I. Nociones Generales, Clima, Hidrología, (ed. en español), Barcelona, Ed. Juventud, 520 p.

DOMINGUES RIBAS, A. (2011). Cosmologia e Geografia Física em Immanuel Kant. Tesi Doctoral. Universidade Estadual de Campinas, Sao Paulo, 342 p. (Disponible en:

http://www.bibliotecadigital.unicamp.br/document/?code=000804783).

FANTONE, V. (2003). Kant, profesor de geografía. Biblioteca Virtual Universsal, 5 p. (disponible en http://www.biblioteca.org.ar/libros/1272.pdf). 
FLAMMARION, C. (1875). La atmósfera: descripción de los grandes fenómenos de la naturaleza. (trad. Luis Barinaga y Corradi). Madrid, Imprenta y Librería de Gaspar, Editores, 428 p.

GIL OLCINA, A. y OLCINA CANTOS, J. (1997). Climatología general. Barcelona, Ed. Ariel. Col. Geografía, 592 .

GLACKEN, C. J. (1996) Huellas en la playa de Rodas. Barcelona, Ed. del Serbal, $729 \mathrm{p}$.

GRAPOTTE, S., LEQUAN, M. and RUFFING, M., (edits.) (2011). Kant et les sciences: Un dialogue philosophique avec la pluralite des savoirs, Ed. Vrin, 388 p.

HADLEY, G. (1735). "Concerning the cause of the general trade-winds", Phil. Trans. 39, 1735-1736, published 1 January 1735. (Ed. Royal Society, on line). En línea:

HARSTSHORNE, R. (1991). "El concepto de geografía como ciencia del espacio: de Kant y Humboldt a Hettner", Documents d'Anàlisi Geogràfica, 18, Universitat Autònoma de Barcelona, 31-54.

JUAN, J. y ULLOA, A. (1748). Observaciones astronómicas, y Phísicas hechas de orden de Su Magestad en los Reynos del Perú, por D. Jorge Juan, Comendador de Aliaga en el Orden de San Juan, Socio Correspondiente de la Real Academia de las Ciencias de París, y D. Antonio de Ulloa, de la Real Sociedad de Londres, ambos Capitanes de Fragata de la Real Armada, de las quales se deduce la figura, y magnitud de la Tierra, y se aplica a la navegación. Madrid (Zúñiga).

JUAN, J. y ULLOA, A. (1748). Relación histórica del viage a la América meridional hecho de orden de Su Magestad para medir algunos grados de Meridiano terrestre, $y$ venir por ellos en conocimiento de la verdadera figura y magnitud de la Tierra, con otras varias observaciones astronómicas, y phisicas, Madrid (Marín).

KANT, I. (1966). Annonce du programme des leçons de M. E. Kant durant le semester d'hiver 1765-1766. Paris, Librairie Philosophique J. Vrin.

KANT, I. (1981). Filosofía de la Historia. México, Fondo de Cultura Económica, 151

KERSZBERG, P. (1984). "La création en mouvement. Essai sur le sens philosophique d une interrogation cosmologique fondamentale dans la Théorie du Ciel". In KANT, Immanuel. Histoire Générale de la Nature et Théorie du Ciel. Paris, Librairie Philosophique J. Vrin, p. 205-259.

LORENTE, J.M. (1930). Meteorología. Barcelona, Editorial Labor, 192 p.

MARCUZZI, M. (1999) "La Géographie kantienne: délimitation de la discipline". In KANT, Immanuel. Géographie. Physische Geographie. Paris. Aubier, p. 40-55.

MARTÍN VIDE, J. (1991). Fundamentos de Climatología Analítica. Madrid, Ed. Síntesis, Madrid, $160 \mathrm{p}$.

MAS GALVAÑ. C. (2014). "El océano vertical. La cuestión de las altitudes en Jorge Juan y Antonio de Ulloa", en Congreso Internacional Jorge Juan Santacilia (1713-1773) en la España de la Ilustración. Memoria y presente. Universidad de Alicante, octubre 2013. (ponencia facilitada por el autor).

MEDINA ISABEL, M. (1976). Meteorología básica sinóptica. Madrid, Ed. Paraninfo, $320 \mathrm{p}$.

OLCINA CANTOS, J. (2013). "Clasificación de las nubes: de Lamarck y Howard al Atlas Internacional de Nubes", en Clima, Naturaleza y desastre. España e Hispa- 
noamérica durante la Edad Moderna (Alberola Romá, A., coord.), Valencia, Publicacions de la Universitat de València, pp. 193-224.

OLCINA CANTOS, J. (2014). "Referencias atmosféricas y avances para la ciencia climática en la obra de José de Acosta". Scripta Nova. Revista Electrónica de Geografía y Ciencias Sociales. [En línea]. Barcelona: Universidad de Barcelona, vol. XVIII, $\mathrm{n}^{\mathrm{o}}$ 478. <http://www.ub.es/geocrit/sn/sn-478.htm>.

ORTEGA VALCARCEL, J. (2000) Los horizontes de la geografía. Teoría de la geografía. Barcelona, Ed. Ariel. Col. Geografía., 604 p.

ORTEGA Y GASSET, J. (1983). Kant, Hegel, Scheler. Madrid, Revista de Occidente en Alianza Editorial, 150 p.

PELKOWSKY, J. (2004). "La anemología kantiana: contexto histórico y versión castellana", Rev. Meteorología Colombiana, 8, 115-127.

PERSSON, A.O. (2006). "Hadley's Principle: Understanding and Misunderstanding the Trade Winds", History of Meteorology, 3, pp. 17-42.

RIBAS, A.D. y VITTE, A.C. (2009). "O Curso de Geografía Física de Immanuel Kant (1724-1804): entre a Cosmología e a Estética". Biblio 3W. Revista Bibliográfica de Geografía y Ciencias Sociales, Universidad de Barcelona, Vol. XIV, ${ }^{\circ}$ 844, 25 de octubre de 2009. <http://www.ub.es/geocrit/b3w-844.htm>.

ROJAS SALAZAR, T. (2007). "Los aportes de Kant a la geografía". Rev. Terra, vol. XXIII, $n^{\circ} 34,11-33$.

RUSSELL, B. (2010). Historia de la Filosofía Occidental. Tomo II (La filosofía moderna). Madrid, Ed. Austral, 550 p.

SEIDENGART, J. (1984). "Genese et structure de la cosmologie kantienne précritique”. In: KANT,Immanuel. Histoire Générale de la Nature et Théorie du Ciel. Paris, Librairie Philosophique J.Vrin, p. 7-59.

URIARTE, A. (2002). Historia del Clima de la Tierra. Vitoria, Servicio Central de Publicaciones del Gobierno Vasco, $306 \mathrm{p}$.

URTEAGA, L. (1993). "La teoría de los climas y los orígenes del ambientalismo", Geocrítica, año XVIII, $\mathrm{n}^{\circ}$ 99, Universidad de Barcelona. Disponible en http://www.ub.edu/geocrit/geo99.htm

VARENIO, B, (1664). Geographia generalis, in qua affectiones generales telluris explicantur. Amstelodami, Ex Officina Elzeviriana, 748 p.

VICUÑA, GUMERSINDO. (1880). Manual de meteorología popular, Madrid, Biblioteca Enciclopédica Popular Ilustrada, 232 p.

WATKINS, E. (edit.) (2001). Kant and the Sciences, Oxford University Press, 304 p.

WATKINS, E. (edit.) (2012). Natural Science. The Cambridge edition of the Works of Immanuel Kant in translation. San Diego, University of California, $818 \mathrm{p}$.

WELTI, R. (2013). La explicación del cielo azul. Una aventura del pensamiento. Rosario, Vesperi Refulgens Editora, 139 p. 